\title{
Linalool Essential Oil/Nanocellulose-Based Pickering Emulsions: An In-Depth Investigation of Processing Parameters
}

\section{Alana Gabrieli de Souza}

Modelagem e Ciências Sociais Aplicadas - CECS/ Universidade Federal do ABC (UFABC) - Santo André Jéssica de Souza Marciano

Modelagem e Ciências Sociais Aplicadas - CECS/ Universidade Federal do ABC (UFABC) - Santo André Rafaela Reis Ferreira

Modelagem e Ciências Sociais Aplicadas - CECS/ Universidade Federal do ABC (UFABC) - Santo André Eder Ramin de Oliveira

Modelagem e Ciências Sociais Aplicadas - CECS/ Universidade Federal do ABC (UFABC) - Santo André Derval dos Santos Rosa ( $\nabla$ dervalrosa@yahoo.com.br)

Modelagem e Ciências Sociais Aplicadas - CECS/ Universidade Federal do ABC (UFABC) - Santo André https://orcid.org/0000-0001-9470-0638

\section{Research Article}

Keywords: Oil-in-water emulsion, Anisotropic nanoparticles, Cellulose nanocrystals, Cellulose Nanofibers, Microdroplets, Design of Experiments.

Posted Date: May 11th, 2021

DOl: https://doi.org/10.21203/rs.3.rs-455128/v1

License: (c) (i) This work is licensed under a Creative Commons Attribution 4.0 International License. Read Full License 


\section{Abstract}

This study aims to prepare nanocellulose-based emulsions using linalool essential oil using different processing parameters and correlating them with emulsions' stability and particle size. The investigated parameters were cellulose morphology (CNC or CNF) and concentration (0.5 or $1 \mathrm{wt} \%)$, essential oil concentration ( 20 or $30 \% \mathrm{v} / \mathrm{v}$ ), homogenization speed $(10,000$ or $12,000 \mathrm{rpm}$ ), and time (3 or 7 minutes). The emulsions were tested by droplet size, morphology, and storage stability. The Design of Experiments (DoE) was used to understand each parameter's effects in the emulsions' characteristics and the statistical results. Each nanocellulose morphology presented a type of stabilization in emulsions and different ideal process parameters. CNC-emulsions showed as optimum parameters $30 \%$ essential oil and 7 minutes preparation, reflecting the higher necessary energy for the efficient CNCs adsorption in the O/W interface, and the maximum stability was $\sim 50 \%$ by electrostatic interactions. CNF-emulsions showed optimum parameters $1 \% \mathrm{CNF}$ and 12,000 rpm homogenization speed, reflecting the necessary parameters to convert the suspensions into gels where the droplets are well-coated by the fibers. This study is a pioneer in an in-depth understanding of the processing parameters' impact on emulsion stability and will be a guideline for future studies with different solid particles and oil phases.

\section{Introduction}

Essential oils (EO) are a popular and widely used class of antimicrobial, antifungal, and antioxidant substances widely used in various applications. According to ISO DIS9235.2 (International Standardization Organization), an EO is "a product prepared by distillation with water or steam or by mechanical processing of citrus peels or by dry distillation of natural materials"(Becerril et al. 2020). Linalool $\left(\mathrm{C}_{10} \mathrm{H}_{18} \mathrm{O}\right)$ is one of the essential oils' main active compounds, being an acyclic monoterpene tertiary alcohol (monoterpenoid) with antimicrobial, antifungal, anti-inflammatory, and antioxidant activities (Herman et al. 2016). It is found in a wide variety of products, cosmetics, and natural essential oils. This compound is considered safe for health since it is not allergic and does not cause sensitization in the skin. However, it presents high volatility, hydrophobicity, intense aroma, photosensitivity, low stability, high susceptibility to oxidation, and solubility (Ribeiro-Santos et al. 2017; Kumar et al. 2020).

Pickering emulsions is an innovative and recent approach used to stabilize emulsions, i.e., oil/water mixtures, using solid particles instead of surfactants. In Pickering emulsions, solid particles are strongly adsorbed at the oil/water interface, forming an irreversible barrier that prevents coalescence. Studies have also shown that stable colloidal emulsions have higher evaporation resistance to volatile oils than systems stabilized with the surfactant, increasing their shelf time and having a controlled release effect that ensures the essential oil's efficiency (Shin et al. 2019; Souza et al. 2020). Initially, Pickering emulsions did not receive much attention due to the limited choices of available materials. With advances in materials science and technology and the growing demand for sustainable options, different green materials have been investigated as possible emulsion stabilizers, such as starch, chitin, gelatin, proteins, and nanocellulose (Feng et al. 2020; Saffarionpour 2020; Yan et al. 2020; Zembyla et al. 2020; Ben Cheikh et al. 2021). 
Nanocellulose is a versatile material with high surface area and varied aspect ratios, depending on its morphology. The nanoscale cellulose has high crystallinity, thermal stability, mechanical properties, and chemical functionality. These multifunctional nanomaterials are mainly found as nanocrystals (CNC) or nanofibers (CNF), and morphology directly impacts the type of emulsion stabilization. The process of adsorption of nanocellulose at the oil and water interface is related to the diffusion of particles by the liquid and its spontaneous positioning of the interfaces of immiscible liquids, which depend on chemical parameters and surface loads. It can be explained by two mechanisms of particle diffusion: in the interface and kinetic adsorption barrier. The adsorption of nanocellulose at the $\mathrm{O} / \mathrm{A}$ interface is therefore dependent on load density, polarity and morphology, and lower load densities are attributed to a lower kinetic adsorption barrier.

Kalashnikova et al. prepared emulsions using nanocrystals of different aspect ratios (cotton $-\mathrm{l} / \mathrm{d}=13$; bacterial cellulose $-\mathrm{I} / \mathrm{d}=47$; Cladophora $-\mathrm{I} / \mathrm{d}=160$ ) (Kalashnikova et al. 2013). The authors verified that CNC with a lower aspect ratio resulted in a denser interface with greater coverage, while the longer CNCs had a different stabilization behavior, forming a network of interconnected droplets. While shorter lengths stabilize electrostatic charges (hydroxyls), longer lengths result in steric impediment in the adjacent region of the adsorbed droplets, resulting in a stable network structure. In CNFs, the surface charge is lower due to the nanoparticles' longer length, and stabilization occurs by the viscoelastic interfacial layers formation, with dominant elastic contributions, generating folds and tangles that facilitate the formation of a three-dimensional network that characterizes the steric stabilization mechanism (Kalashnikova et al. 2013; Gestranius et al. 2017).

Besides the solid particle type and characteristics, Pickering emulsions quality and characteristics are extremely important, aiming at broad applicability and a long storage time. Pickering emulsion stability is mainly related to process parameters and emulsification systems characteristics, such as particle size and intrinsic characteristics, oil characteristics, system energy level, and preparation time. Although the literature presents several studies of stabilized emulsions (Gestranius et al. 2017; Almasi et al. 2020; Trujillo-Cayado et al. 2020; Yu et al. 2021), evaluating the impact of emulsification on essential oils' bioactive properties and the adsorption effectiveness, few studies still bring quantitative data about process design. Yao et al. investigated the Pickering emulsion stability using a microfluidic method and polystyrene as solid particles, controlling the particle adsorption (Yao et al. 2018). The authors verified controlled the particle size and the droplets surface corage and presented important results in this field.

This work's objective was to expand the information about the process parameters and project design through an in-depth investigation of Pickering emulsion properties' processing conditions. Nanocellulose was used as a green solid-phase, and two morphologies were used: nanocrystals and nanofibers, and two concentrations ( 0.5 and $1 \mathrm{wt} \%$ ). Besides, the processing time, homogenization speed, and essential oil concentration were varied. The results were followed by monitoring droplet size, morphology, and storage stability. The Design of Experiments (DoE) was used to understand each parameter's effects in the emulsions' characteristics. 


\section{Materials And Methods}

\subsection{Materials}

The cellulose nanofibrils (CNF) were kindly provided by Suzano Papel e Celulose (São Paulo, Brazil). Cellulose nanocrystals (CNC) were prepared according to the methodology described in our previous work, as well as their complete characterization (Lima et al. 2018; Souza et al. 2019). Chemical reagents with analytical grade were purchased from Sigma-Aldrich (São Paulo, Brazil). Ferquima Indústria e Comércio Ltda. (São Paulo, SP, Brazil) provided the Ho wood (Cinnamomum camphora var. linalooliferum, CAS Number 92201-50-8) essential oil.

Briefly, the CNFs presented a diameter of $66.3 \pm 20.5 \mathrm{~nm}$ and length of $4.0 \pm 1.0 \mu \mathrm{m}$, with $L / D=60$, and zeta potential of $-33.2 \pm 3.2 \mathrm{mV}$ (Souza et al. 2020). CNCs had an average length of $2.0 \pm 0.8 \mu \mathrm{m}$ and mean diameter of $131.1 \pm 29.6 \mathrm{~nm}$, with $L / D=15$, and zeta potential of $-33.0 \pm 1.0$ (Lima et al. 2019).

\subsection{Methods}

For the emulsion's preparation, the essential oil was mixed with a previously dispersed CNC or CNF solution, and the mixture was homogenized in an Ultra-Turrax Blender, IKA T25 model (IKA Werke, Staufen, Germany).

The adopted parameters for investigation were based on an extensive literature search, aiming to establish maximum and minimum values appropriate for adequate emulsion stability. The adopted parameters were: nanocellulose morphology (CNC or CNF), nanocellulose concentration (0.5 or 1 wt\%), homogenization speed $(10,000 \mathrm{rpm}$ or $12,000 \mathrm{rpm})$, essential oil concentration (20 or $30 \% \mathrm{~V} / \mathrm{v})$, and processing time ( 3 or 7 minutes). Figure 1 shows a schematic representation of the adopted methodology, considering the selected processing parameters and their effect on mixture oil/water emulsification.

The present work generated an experimental design using Design-Expert ${ }^{\circledR}$ software (Trial version 12.0.0, StatEase, Inc., USA). For this, it was conducted a Regular two-level factorial design, using the configuration $2^{5-1}$. The samples were named with numbers, as shown in Table 2, and there is no order followed because, according to the principle of DoE, randomly performed tests reduce associated operational and environmental errors. Design-Expert ${ }^{\circledR}$ was also used for the evaluation of the statistical experimental design. In Table 2, the black numbering represents the oil and water mixtures, the blue numbering represents the samples stabilized with CNF, and the red samples are assigned with CNC.

Table 2. Compositions prepared from the linalool essential oil, with the preparation parameter used and its respective numerical nomenclature. 


\begin{tabular}{|c|c|}
\hline Number & Processing characteristics \\
\hline 1 & $12,000 \mathrm{rpm}, 20 \%$ oil, 3 minutes \\
\hline 2 & $10,000 \mathrm{rpm}, 20 \%$ oil, 7 minutes \\
\hline 3 & $0.5 \% \mathrm{CNF}, 10,000 \mathrm{rpm}, 20 \%$ oil, 3 minutes \\
\hline 4 & $0.5 \% \mathrm{CNF}, 10,000 \mathrm{rpm}, 30 \%$ oil, 7 minutes \\
\hline 5 & $1 \% \mathrm{CNC}, 12,000 \mathrm{rpm}, 30 \%$ oil, 3 minutes \\
\hline 6 & $0.5 \% \mathrm{CNC}_{3}, 10,000 \mathrm{rpm}, 30 \%$ oil, 3 minutes \\
\hline 7 & $1 \% \mathrm{CNC}, 10,000 \mathrm{rpm}, 20 \%$ oil, 3 minutes \\
\hline 8 & $0.5 \% \mathrm{CNC}, 12,000 \mathrm{rpm}, 20 \%$ oil, 3 minutes \\
\hline 9 & $1 \% \mathrm{CNC}, 10,000 \mathrm{rpm}, 30 \%$ oil, 7 minutes \\
\hline 10 & $1 \% \mathrm{CNF}, 12,000 \mathrm{rpm}, 30 \%$ oil, 7 minutes \\
\hline 11 & $0.5 \% \mathrm{CNC}, 12,000 \mathrm{rpm}, 30 \%$ oil, 7 minutes \\
\hline 12 & $0.5 \% \mathrm{CNF}, 12,000 \mathrm{rpm}, 30 \%$ oil, 3 minutes \\
\hline 13 & $1 \%$ CNF, $10,000 \mathrm{rpm}, 30 \%$ oil, 3 minutes \\
\hline 14 & $0.5 \% \mathrm{CNF}, 12,000 \mathrm{rpm}, 20 \%$ oil, 7 minutes \\
\hline 15 & $10,000 \mathrm{rpm}, 20 \%$ oil, 3 minutes \\
\hline 16 & $10,000 \mathrm{rpm}, 30 \%$ oil, 3 minutes \\
\hline 17 & $1 \% \mathrm{CNF}, 12,000 \mathrm{rpm}, 20 \%$ oil, 3 minutes \\
\hline 18 & $0.5 \% \mathrm{CNC}, 10,000 \mathrm{rpm}, 20 \%$ oil, 7 minutes \\
\hline 19 & $12,000 \mathrm{rpm}, 30 \%$ oil, 3 minutes \\
\hline 20 & $12,000 \mathrm{rpm}, 20 \%$ oil, 7 minutes \\
\hline 21 & $12,000 \mathrm{rpm}, 30 \%$ oil, 7 minutes \\
\hline 22 & $10,000 \mathrm{rpm}, 30 \%$ oil, 7 minutes \\
\hline 23 & $1 \% \mathrm{CNC}, 12,000 \mathrm{rpm}, 20 \%$ oil, 7 minutes \\
\hline 24 & $1 \% \mathrm{CNF}, 10,000 \mathrm{rpm}, 20 \%$ oil, 7 minutes \\
\hline
\end{tabular}

\subsection{Characterization}

Dynamic light scattering

Emulsions diluted to $0.05 \%$ in distilled water were submitted to Dynamic Light Scattering Analysis (DLS) to evaluate the droplets' average size. The analyses were performed on ALV-CGS3 equipment (ALV-GmbH, Langen, Germany), with a 90 angle, equipped with polarized HeNe laser (22 $\mathrm{mW}$ ), a wavelength of 633 $\mathrm{nm}$, and a pair of APD detectors operating in pseudo-correlation mode. The data were treated with Origin 8 software.

\section{Optical microscopy}

The emulsions microstructures were analyzed under a Leica DM KM optical microscope (Leica Microsystems GmbH, Wetzlar, Germany). An emulsion drop was added to a glass slide, and representative images were obtained. With such images, the droplets' diameters were measured using the ImageJ software, with an average of at least 120 drops. 
Fresh samples were added to glass tubes and stored at room temperature. The emulsions stability (\%) was measured on days $0,10,15,21$, and 30, in duplicate. The stability index was expressed as the volume formed by the emulsion layer $\left(V_{\text {emuls }}\right)$ to the total sample volume $\left(V_{\text {total }}\right)$, as presented in Equation 1.

$$
I E=\frac{V_{E m u l s a ̃ o}}{V_{\text {total }}} * 100
$$

\section{Characterization}

The linalool essential oil and water mixtures, without stabilizing agent, immediately after its preparation (i.e., on the first day) are presented in Fig. 1S (Supplementary Material), with their respective nomenclature. These samples are slightly opaque with visible transparency, indicating low emulsification capacity, a characteristic usually reported for mixtures of immiscible liquids and distinct polarities (Shin et al. 2019). The oily and aqueous phases are not identifiable due to the staining of linalool essential oil, which is transparent and indistinguishable from water. The emulsions stabilized by CNC or CNF immediately after their preparation are presented in Fig. 2S. All emulsions showed the characteristic turbidity of emulsified samples, indicating that the emulsification methodology adopted was adequate. In the samples stabilized with CNC, no emulsion presented immediate phase separation after preparation, i.e., there was no immediate coalescence, and possibly the CNCs acted in the shielding of the droplet interface, avoiding its approximation (Tang et al. 2018). The emulsions stabilized by CNF presented a similar appearance, with high apparent turbidity, indicating successful emulsification.

\subsection{Droplets' sizes}

Two methods were used to measure the droplet sizes: DLS and optical microscopy. The techniques were used in a complementary way since DLS measures droplets that vary between nanometers and some micrometers, and this measurement is associated with Brownian movement of particles and drops, and the smaller the particle, the faster its movement. This technique does not measure the amount of light dispersed, but the dynamics of light disperses in short periods, at a fixed angle, being measured as a correlation function. Therefore, the size distribution calculation depends on the dispersion of light resulting from the emulsion droplets (Friberg et al. 2004). For optical microscopy, magnifying lenses and light incidence are used to visualize the emulsion microstructure. However, since it uses wavelength in visible light, there is a limitation of the measured particle sizes, restricted to micrometric particles.

The emulsions were submitted to DLS measurements on day zero after preparing the oil/water mixtures and dilution. The samples without stabilization did not present measurement readings, indicating that no 
drops were detected with sizes below the equipment's measurement limit, $\sim 15 \mu \mathrm{m}$, regardless of the process conditions. Figure 2 shows the droplet sizes $\left(D_{H}\right.$ hydrodynamic diameter, in $\left.\mu \mathrm{m}\right)$ obtained for emulsions stabilized with CNC or CNF.

Among the emulsions stabilized with CNC (Fig. 2a), the majority presented similar diameters ranging between 0.02 and $1 \mu \mathrm{m}$, except for samples 7 (1\% CNC, 10,000 rpm, 20\% oil, 3 minutes) and 9 (1\% CNC, $10,000 \mathrm{rpm}, 30 \%$ oil, 7 minutes), which presented larger sizes, with $1.03 \pm 0.005 \mu \mathrm{m}$ and $2.6 \pm 0.03 \mu \mathrm{m}$, respectively. Both samples have in common the lowest homogenization speed of 10,000 rpm and higher CNC concentrations ( $1 \%)$, indicating that, for Linalool/water/CNC emulsions, the rotation and concentration of cellulose nanocrystals are important parameters.

Figure $2 b$ shows the $D_{H}$ of emulsions stabilized with CNF, and most samples showed similar droplet diameters. Two samples showed different size' pattern, with diameters greater than $35 \mu \mathrm{m}: 3(0.5 \% \mathrm{CNF}$, $10,000 \mathrm{rpm}, 20 \%$ oil, 3 minutes) and 12 (0.5\% CNF, 12,000 rpm, 30\% oil, 3 minutes), and these emulsions have in common the preparation time and cellulose nanofibers content, indicating that both parameters have a significant influence on the emulsified system quality. Visually, both emulsions showed instability (Fig. 2S), e.g., sample 3 presented an aqueous layer, while sample 12 has a superior oily layer. These phenomena indicate a droplets coalescence tendency and, consequently, increased phase separation.

For the emulsified systems understanding, particle sizes' joint analysis is necessary, which is complimentary. Thus, the optical microscopy analysis was performed, and the average diameters results of the oil/water samples and stabilized with CNC or CNF are presented in Figs. 2c-e. Due to the difference in the light source and wavelength, significantly larger particles are measured by this technique. For the measurements, the samples were subtly agitated before the analysis.

Figure $2 \mathrm{c}$ shows the average diameters of samples without stabilizer, with values of $\sim 100 \mu \mathrm{m}$, while after CNC stabilization, droplet sizes were $\sim 50 \mu \mathrm{m}$ (Fig. 2d). This variation in sizes is associated with stabilization efficiency with cellulose nanocrystals, which avoid the oil droplets approximation and coalescence due to their electrostatic charges generated by cellulose hydroxyls (Bai et al. 2019; Shin et al. 2019). For emulsions containing CNF (Fig. 2e), there was a significant variation between the samples, which can be explained by the gel-like formation, in which the drops are trapped inside the threedimensional structure formed by cellulose nanofibers resulting in apparent larger sizes (Lu et al. 2019, 2021).

Visually, due to the standard deviation, the samples have similar sizes, and it is not possible to identify significant variations in droplet size. For a more detailed analysis, a statistical treatment was applied, using the One-Way ANOVA method and the Tukey test to evaluate the systems' similarity. Table 2 presents the Tuckey test results, comparing pairs of oil/water samples without the nanocellulose use, where the colored cells represent statistically different samples.

Table 2. Tukey test for the mixtures of linalool essential oil and water, without stabilizer, for droplets measured by optical microscopy on day 0 . 


\begin{tabular}{|c|c|c|c|c|c|c|c|c|}
\hline & 1 & 2 & 15 & 16 & 19 & 20 & 21 & 22 \\
\hline 1 & & 0.064 & 0.003 & 1 & 0.721 & $2.67 \times 10^{-6}$ & 0.040 & 0.023 \\
\hline 2 & 4.168 & & 0.882 & 0.013 & 0.869 & 0.082 & $7.84 \times 10^{-11}$ & 0.999 \\
\hline 15 & 5.462 & 1.898 & & 0.004 & 0.190 & 0.931 & $2.11 \times 10^{-12}$ & 0.988 \\
\hline 16 & 0.396 & 4.889 & 6.153 & & 0.446 & $6.65 \times 10^{-8}$ & 0.056 & 0.004 \\
\hline 19 & 2.331 & 1.944 & 3.558 & 2.904 & & 0.001 & $2.82 \times 10^{-6}$ & 0.625 \\
\hline 20 & 7.607 & 4.045 & 1.702 & 8.531 & 5.778 & & 0 & 0.300 \\
\hline 21 & 4.402 & 10.02 & 10.71 & 4.238 & 7.592 & 13.92 & & $1.49 \times 10^{-11}$ \\
\hline 22 & 4.651 & 0.682 & 1.241 & 5.374 & 2.536 & 3.238 & 10.36 & \\
\hline
\end{tabular}

The results indicate that sample 21 (12,000 rpm, 30\% oil, 7 minutes) presents statistically different results, with the largest drop sizes, which may be an indication that extreme preparation conditions, e.g., highest rotation, oil concentration, and time, can result in a non-beneficial system disturbance, inducing a spontaneous and immediate coalescence. Sample 19 (12,000 rpm, 30\% oil, 3 minutes) presents the most significant similarity with the others since it has intermediate drop sizes. Compared to sample 21, its preparation characteristics indicate that time is a relevant factor for preparing emulsified systems and may be associated with its entropy and, consequently, its stability. Moreover, when doing a peer analysis, it was impossible to correlate the parameters of oil concentration and homogenization speed, which can be justified by the absence of stabilizers and miscibility between liquids. For example, sample $1(12,000$ rpm, $20 \%$ oil, 3 minutes) showed similarity with 2 (10,000 rpm, 20\% oil, 7 minutes), 16 (10,000 rpm, 30\% oil, 3 minutes) and 19 (12,000 rpm, 30\% oil, 3 minutes). By comparing process parameters, there is no constant associated similarity or differences in drop size values.

Table 3 presents the statistical comparison for emulsions stabilized with cellulose nanocrystals, and the results presented samples with high statistical similarity, and only sample $6(0.5 \% \mathrm{CNC}, 10,000 \mathrm{rpm}, 30 \%$ oil, 3 minutes) presented different diameters (and higher than the others). In this case, the samples' analysis on day 0 indicated a drop size pattern, and it was necessary a temporal follow-up, and complementary analyses identify possible processing effects. This result was expected since in Fig. $2 \mathrm{~S}$ there was no visual distinction between the samples, indicating a possible similarity after preparation.

Table 3. Tukey test for linalool, water, and CNC emulsions for droplets measured by optical microscopy on day 0 .

\begin{tabular}{|c|c|c|c|c|c|c|c|c|}
\hline & 5 & 6 & 7 & 8 & 9 & 11 & 18 & 23 \\
\hline 5 & & $8.61 \times 10^{-6}$ & 0.797 & 1 & 0.939 & 0.100 & 0.583 & 1 \\
\hline 6 & 7.288 & & 0.014 & $2.26 \times 10^{-5}$ & 0.007 & 0.000 & $6.71 \times 10^{-11}$ & $1.01 \times 10^{-6}$ \\
\hline 7 & 2.149 & 4.867 & & 0.743 & 1 & 0.961 & 0.020 & 0.618 \\
\hline 8 & 0.285 & 7.019 & 2.279 & & 0.903 & 0.999 & 0.799 & 1 \\
\hline 9 & 1.661 & 5.122 & 0.406 & 1.824 & & 0.995 & 0.069 & 0.839 \\
\hline 11 & 0.620 & 6.566 & 1.524 & 0.858 & 1.062 & & 0.309 & 0.997 \\
\hline 18 & 2.621 & 10.05 & 4.714 & 2.142 & 4.136 & 3.217 & & 0.723 \\
\hline 23 & 0.360 & 7.856 & 2.55 & 0.041 & 2.036 & 0.991 & 2.326 & \\
\hline
\end{tabular}


Table 4 illustrates the statistical comparison for emulsions stabilized with cellulose nanofibers. The samples with the highest statistical differences were those with larger droplet sizes, while those with similarities are attributed to smaller diameters. Sample 3 (0.5\% CNF, 10,000 rpm, 20\% oil, 3 minutes) showed statistical similarity with 4 ( $0.5 \% \mathrm{CNF}, 10,000 \mathrm{rpm}, 30 \%$ oil, 7 minutes), 12 (0.5\% CNF, 12,000 rpm, $30 \%$ oil, 3 minutes) and 14 ( $0.5 \%$ CNF, 12,000 rpm, $20 \%$ oil, 7 minutes), and all have as a common factor the CNF concentration.

Table 4. Tukey test for linalool, water, and CNF emulsions for droplets measured by optical microscopy on day 0 .

\begin{tabular}{|c|c|c|c|c|c|c|c|c|}
\hline & 3 & 4 & 10 & 12 & 13 & 14 & 17 & 24 \\
\hline 3 & & 1 & $1.65 \times 10^{-5}$ & 0.961 & 0 & 0.999 & 0.043 & $2.42 \times 10^{-8}$ \\
\hline 4 & 0.525 & & $7.27 \times 10^{-6}$ & 0.999 & 0 & 0.986 & 0.021 & $1.22 \times 10^{-8}$ \\
\hline 10 & 7.103 & 7.329 & & $2.53 \times 10^{-9}$ & 0.018 & $8.20 \times 10^{-5}$ & 0.207 & 0.981 \\
\hline 12 & 1.527 & 0.863 & 9.263 & & 0 & 0.664 & $7.34 \times 10^{-5}$ & 0 \\
\hline 13 & 11.89 & 11.94 & 4.746 & 14.41 & & 0 & $3.23 \times 10^{-8}$ & 0.185 \\
\hline 14 & 0.752 & 1.261 & 6.64 & 2.455 & 11.58 & & 0.139 & $1.38 \times 10^{-7}$ \\
\hline 17 & 4.365 & 4.712 & 3.502 & 6.673 & 8.687 & 3.748 & & 0.007 \\
\hline 24 & 8.755 & 8.912 & 1.34 & 11.22 & 3.573 & 8.343 & 5.152 & \\
\hline
\end{tabular}

Unlike observed for CNCs, the CNFs present a limit concentration so that they are efficient against agglomeration, and above this value, the droplets have significantly larger diameters. Similarly, the samples stabilized with $1 \%$ CNF showed similarity to each other. However, due to the visual aspect, it is impossible to identify whether, in the samples stabilized with CNF, stability is directly related to the droplets' size or the stabilization mechanism (gel formation through a three-dimensional network). Analyzing the droplet sizes by DLS, optical microscopy, and statistics, it was found that the smallest droplets, measured by DLS, were found for $1 \%$ CNF. In contrast, for optical microscopy results, this behavior was reversed, which may indicate stability for smaller droplets and the larger droplets resulting from the oily phase retained between the polymeric nanofibers, possibly resulting in the absence of phase separation.

\subsection{Emulsions' morphology}

Optical microscopy was used for droplets shape visual analysis. The mixture between oil and water results in two distinct and completely identifiable phases, as shown in Fig. 3S, and shortly after mixing, a momentary formation of oily drops occurs. However, due to instability, during the analysis, a coalescence trend was observed.

Figure 3 presents representative photomicrographs for emulsions stabilized with cellulose nanocrystals, and these presented well-defined droplets with a spherical shape, with large size distribution, i.e., high polydispersity, which may be associated with an insufficient coating of particles by CNCs (Varanasi et al. 2018).

It is also observed droplets similar to small "dots" associated with DLS analysis' micrometric sizes. It is not possible to observe indications of nanoparticles' presence due to equipment limitations since the 
optical microscope has no resolution for the visualization of particles on the nanoscale, and this effect is more pronounced for samples $9,11,18$, and 23 . These samples have a common factor the longer preparation time (7 minutes), indicating that longer homogenization times contribute to the droplets breakage in smaller droplets due to the higher disruptive energy available, resulting in greater surface area to be covered by CNC (Bai et al. 2019). However, due to the CNC rigid characteristic, it was expected that the CNCs concentration was an influential factor for obtaining smaller drops due to its effect on the alteration of energy distribution, which was not verified. These results indicate that, in the present study, the emulsions' viscosity was not significantly altered by the nanoparticles' concentration.

There is no logical influence pattern of the oil concentration parameter since smaller and larger sizes are distributed randomly. These results indicate that, for linalool emulsions stabilized with CNC, an oily phase content value was not reached that can be adequately stabilized, dependent on the other parameters. Another characteristic of strong influence on stability is the oil polarity and viscosity, which can generate intrinsically larger drops to other oils to the aqueous phase. Due to the essential oil chains arrangement, larger drops can generate a very high kinetic barrier to be overcome and break the drops into smaller sizes (Saffarionpour 2020). As described above, there was no statistically significant variation in particle sizes, a factor that was corroborated by the images presented.

Figure 4 illustrates the morphology of emulsions stabilized with cellulose nanofibers. Unlike that observed for CNC emulsions, they have a cloudy background and indications of heterogeneity in the samples. Turbidity and irregularity are gel characteristics, and this behavior is more pronounced for samples 13,17 , and 10 , which have as a common parameter the CNF concentration of $1 \%$, indicating that smaller concentrations are not sufficient for the formation of a stable three-dimensional structure, resulting in the free movement of oil drops and their approximation (instability mechanism) (Kalashnikova et al. 2011; Angkuratipakorn et al. 2017). According to Li et al., the formation of a gel layer decreases the tendency to coalescence due to steric impairments caused by fibers (Li et al. 2019b). Lu et al. reported that, under appropriate process conditions, fibrillar nanoparticles' higher concentrations could increase the system's gelling, making it stronger and, consequently, more stable, reflecting in emulsions with long-term stability (Lu et al. 2021).

Of the three samples that stood out, it is possible to observe that sample 13 ( $1 \% \mathrm{CNF}, 10,000 \mathrm{rpm}, 30 \%$ oil, 3 minutes) presented droplet sizes larger than the other samples, which can be attributed to low rotation speed processing time, which did not allow an adequate breakage of droplets in smaller droplets. In addition to the gel structure, another important point is that all samples stabilized with CNF presented indistinguishable droplets (points), which can be attributed to the CNFs elongated and flexible morphology and their ability to bind or overlap on the water surface of the oil. The larger drops observed for all emulsions result from the three-dimensional network formed, in which the droplets tend to disperse in porous space, and this dispersion caused by the Brownian movement in the aqueous phase approximates the droplets, resulting in the coalescence phenomena (Lu et al. 2021). 
Comparing emulsions stabilized with CNC and CNF, it was found that particle morphology is an essential factor for the stability of linalool/water essential oil systems due to electrostatic stability mechanisms, resulting from intrinsic loads from cellulose hydroxyls, particle flexibility, and migration of them to the oil/water interface. In this case, cellulose nanofibers may have presented more stable results due to their hydrodynamic interactions, such as the long-range capillary attraction forces induced by the deformation of fluid-fluid interfaces, dominating the CNF migration at the interface and result in the confinement of drops within the formed network (Kalashnikova et al. 2013).

\subsection{Stability under storage}

Oil/water samples were prepared for comparison with stabilized ones. It was verified that there was complete phase separation between oil and water from the preparation moment, i.e., the samples are entirely unstable and immiscible due to the polarity difference. Figure 5 shows the digital photographs obtained for days 0 and 30 to compare the mixtures' stability.

Figure 6 shows the digital photographs obtained for days 0 and 30 to compare the CNC-emulsions stability. For these samples, the interest phase was the emulsified part, considered as stable. The instability phenomenon was more significant for samples 7 (1\% CNC, 10,000 rpm, 20\% oil, 3 minutes), 8 ( $0.5 \%$ CNC, $12,000 \mathrm{rpm}, 20 \%$ oil, 3 minutes), and 23 (1\% CNC, $12,000 \mathrm{rpm}, 20 \%$ oil, 7 minutes), with the stability value below $30 \%$, as shown in Table 5 , and the three samples have as a common factor the lowest essential oil concentration.

The samples showed a non-adsorbed CNC sedimented fraction, an aqueous phase, and the top's emulsified phase. The sedimentation results from the nanoparticles' attraction to each other, which are strong enough to avoid their deposition at the oil/water interface, forming particle clusters later flocculated. This behavior is called entropy-driven (Lu et al. 2021).

The two most stable samples stabilized with CNC were 9 ( $1 \%$ CNC, 10,000 rpm, $30 \%$ oil, 7 minutes) and 11 ( $0.5 \%$ CNC, $12,000 \mathrm{rpm}, 30 \%$ oil, 7 minutes), with values above $39 \%$, indicating that for cellulose nanocrystals, time can be a decisive factor for obtaining stable emulsions. These results indicate that the emulsion stability is dependent on a factor combination that needs to occur to be a good coating of oil drops by nanoparticles (Bai et al. 2019; Shin et al. 2019).

Table 5. Stability values over time for linalool and water mixtures and their emulsions. Red lines indicate samples stabilized with CNC, and blue lines, samples stabilized with CNF. 


\begin{tabular}{|c|c|c|c|c|c|}
\hline \multirow{2}{*}{ Sample } & \multicolumn{5}{|c|}{ Stability [\%] } \\
\cline { 2 - 6 } & Day 0 & Day 10 & Day 15 & Day 21 & Day 30 \\
\hline $\mathbf{1}$ & - & - & - & - & - \\
\hline $\mathbf{2}$ & - & - & - & - & - \\
\hline $\mathbf{3}$ & 75.9 & 74.6 & 74.0 & 72.1 & 71.9 \\
\hline $\mathbf{4}$ & 83.2 & 82.0 & 75.0 & 72.9 & 72.7 \\
\hline $\mathbf{5}$ & 100 & 100 & 42.4 & 42.2 & 34.0 \\
\hline $\mathbf{6}$ & 100 & 44.3 & 44.0 & 41.9 & 38.2 \\
\hline $\mathbf{7}$ & 100 & 36.1 & 29.3 & 25.1 & 23.0 \\
\hline $\mathbf{8}$ & 100 & 100 & 25.1 & 23.9 & 23.9 \\
\hline $\mathbf{9}$ & 100 & 54.0 & 48.2 & 47.2 & 43.4 \\
\hline $\mathbf{1 0}$ & 100 & 96.3 & 95.7 & 94.4 & 97.0 \\
\hline $\mathbf{1 1}$ & 100 & 44.8 & 41.2 & 42.2 & 39.6 \\
\hline $\mathbf{1 2}$ & 77.8 & 79.2 & 73.9 & 73.7 & 72.4 \\
\hline $\mathbf{1 3}$ & 88.0 & 88.3 & 86.6 & 85.3 & 85.5 \\
\hline $\mathbf{1 4}$ & 82.9 & 82.4 & 79.2 & 79.0 & 77.4 \\
\hline $\mathbf{1 5}$ & - & - & - & - & - \\
\hline $\mathbf{1 6}$ & - & - & - & - & - \\
\hline $\mathbf{1 7}$ & 100 & 100 & 100 & 100 & 100 \\
\hline $\mathbf{1 8}$ & 100 & 100 & 24.9 & 20.1 & 36.8 \\
\hline $\mathbf{1 9}$ & - & - & - & - & - \\
\hline $\mathbf{2 0}$ & - & - & - & - & - \\
\hline $\mathbf{2 1}$ & - & - & - & - & - \\
\hline $\mathbf{2 2}$ & - & - & - & - & - \\
\hline $\mathbf{2 3}$ & 100 & 30.4 & 25.7 & 25.2 & 15.2 \\
\hline $\mathbf{2 4}$ & 100 & 100 & 100 & 95.6 & 94.6 \\
\hline
\end{tabular}

* The symbol "-" represents no emulsified phase, and therefore it was not possible to calculate the samples' stability.

For CNF-emulsions (Figure 7), the stability values were significantly higher than that of CNC after 30 days, and the lowest stability was verified for 3 ( $0.5 \%$ CNF, 10,000 rpm, 20\% oil, 3 minutes), 4 ( $0.5 \%$ CNF, 10,000 rpm, 30\% oil, 7 minutes), and 12 ( $0.5 \%$ CNF, 12,000 rpm, 30\% oil, 3 minutes), with values of $71.9,72.7$ and $72.4 \%$. These samples have the lowest CNF content in common, indicating that, for nanofibrillar morphology, higher contents induce greater emulsification. The most stable samples were 10 ( $1 \% \mathrm{CNF}$, $12,000 \mathrm{rpm}, 30 \%$ oil, 7 minutes) and 17 (1\% CNF, 12,000 rpm, 20\% oil, 3 minutes), with values of 97 and $100 \%$. These high stability values are associated with van der Waal forces, hydrogen bonds, colloidal interactions associated with DLVO theory (Derjaduin-Landau-Verwey-Overbeek), and capillary forces (Li et al. 2019a).

For linalool essential oil, essential oil concentration and time are factors that do not influence stability, while the others are an essential combination for stabilization (Jiménez Saelices and Capron 2018). Similar results regarding the concentration of CNFs were reported by Paximada et al. that investigated the 
use of bacterial cellulose nanofibrils as a stabilizer of oil/water emulsions (Paximada et al. 2016). Besides, while the linalool-CNC emulsions presented an emulsified behavior of a more liquid aspect, the linalool-CNF emulsions showed a gel-like behavior, and no excess oil layers were observed.

The variation of values between morphologies is associated with the aspect ratio and stabilization methodology, since CNCs stabilize via electrostatic interactions (stabilization associated with nanoparticle and essential oil intrinsic characteristics, such as surface charges and chemical structures), and CNFs form a three-dimensional network that traps the oil droplets inside and avoids their approximation (Lu et al. 2021).

\subsection{Design of experiments}

The DoE was carried out in a simplified way, using each parameter's minimum and maximum values to prepare emulsions. The results used for this analysis were the stability values on day 30 and the particle sizes in the micrometric range, obtained by optical microscopy, also for day 30 . The results of the oil/water mixtures were not considered because, as previously reported, the mixtures are unstable. The design of experiments was used to analyze the sample set and verify, in a simplified way, the parameters that significantly influence the emulsion formation and stability.

Considering the stability results, for statistical analysis, ANOVA was used for the reduced 2FI model, and the $\mathrm{F}$ model value was 5.49 , i.e., the model is significant. The $\mathrm{R}^{2}$ was 0.9083 for stability and 0.9795 for particle size, indicating a good fit. Also, $P$ values less than 0.050 indicate that the terms of the model are significant. In this case, the DoE is a meaningful and valid model term. Thus, the design results are correct and can be used with statistical confidence.

Figure 8 presents the response surface obtained for stability, and the CNC-emulsions indicated that the essential oil concentration is a factor that does not influence the stability values, not being a key parameter for the preparation of the emulsions.

The results indicated that for shorter process times and speeds, stability increased (red color) with higher EO concentrations and lower CNC concentrations. By maintaining the speed and increasing the time, there was a linear trend, with better oil concentration remaining at $30 \%$ and the CNC concentration being variable, according to the selected configuration. By DoE, considering the preparation time and its impact on stability, it was impossible to identify the best conditions, and therefore, the experimental results were essential, as described earlier. Moreover, CNC concentration was not shown as a significant influence parameter, i.e., the appropriate concentration required an analysis of the combination with the other factors.

The same analysis was performed considering the particle sizes, as shown in Fig. 9, verifying no linearity of the process parameters' actions. Each parameter possibly directly affects the others, e.g., the staging time and the homogenization speed are directly linked. 
Considering the theoretical and experimental stability results, samples 5 ( $1 \% \mathrm{CNC}, 12,000 \mathrm{rpm}, 30 \%$ oil, 3 minutes), 6 ( $0.5 \%$ CNC, 10,000 rpm, 30\% oil, 3 minutes), 9 (1\% CNC, 10,000 rpm, 30\% oil, 7 minutes) and 11 ( $0.5 \%$ CNC, $12,000 \mathrm{rpm}, 30 \%$ oil, 7 minutes) stand out. The other parameters were analyzed together with the results previously presented, and the samples that presented better emulsification capacity, stability, and adequate droplet sizes, for CNC-emulsions were 9 ( $1 \%$ CNC, 10,000 rpm, 30\% oil, 7 minutes) and 11 ( $0.5 \%$ CNC, $12,000 \mathrm{rpm}, 30 \%$ oil, 7 minutes), having in common $30 \%$ essential oil and 7 minutes of preparation time. This result may be correlated with the linalool chemical structure, resulting in hydrogen bonds with CNCs, altering emulsion stabilization due to its free hydroxyls. For this reason, the highest times are necessary to guarantee an adequate $\mathrm{CNC}$-adsorption onto oil/water interfaces since the system receives more energy during longer emulsification processes.

The same analysis was performed for CNF-emulsions, as shown in Fig. 10. Different from that observed for CNC emulsions, there is a well-defined pattern for each parameter influence. The highest stability values (red color) were observed for samples containing $1 \%$ cellulose nanofibers, i.e., it was necessary to use larger CNF amounts to achieve a stable and adequate three-dimensional network for this emulsions type, and, therefore, of the 8 compositions investigated, the DoE analysis decreases the initial number to 4 samples: 10 (1\% CNF, 12,000 rpm, 30\% oil, 7 minutes), 13 (1\% CNF, 10,000 rpm, 30\% oil, 3 minutes), 17 ( $1 \%$ CNF, 12,000 rpm, $20 \%$ oil, 3 minutes) and 24 (1\% CNF, 10,000 rpm, $20 \%$ oil, 7 minutes). The concentration of $1 \%$ was associated with the necessary concentration to reach a critical level to guarantee long-range hydrodynamic interactions between the fibers, generating a percolation path and ensuring that the suspension passes to the gel state and that most drops were well coated, avoiding their coalescence.

Another parameter that influences emulsion stability is the homogenization speed, and the highest stability values and the trend of more stable emulsions were observed for $12,000 \mathrm{rpm}$. The high homogenization speed reflects the need for a high amount of energy. The oily phase dissociation and droplet reorganization into smaller droplets are necessary for cellulose nanofibers' dispersion (long and flexible fibers) and forming a gel-like structure. By the response surface graphs, it is verified that lower rotations do not provide enough energy for efficient homogenization and a possible adequate droplets coverage, indicating that the system energy is an essential parameter to ensure a stable emulsion, being associated with the free energy necessary to overcome the phase separation energy barrier.

Figure 11 presents the response surface graphs obtained for the droplet size for the evaluation of process variables. Similar to that observed for stability, the main parameters are speed, and at 10,000 rpm, the largest drop sizes were observed (i.e., they have the greater surface area and lower coverage of the interface containing CNFs). The essential oil again presented itself as a parameter without significant influence. The most stable samples were 10 (1\% CNF, 12,000 rpm, 30\% oil, 7 minutes) and 17 (1\% CNF, $12,000 \mathrm{rpm}, 20 \%$ oil, 3 minutes).

Figure 12 presents the main results obtained for the emulsions studied in this work, considering the processing parameters. 


\section{Conclusions}

This study evaluated different process parameters to prepare linalool/nanocellulose-based Pickering emulsions, bringing in-depth understandings about each factor's importance and highlighting which items are important for linalool emulsions preparation. The parameters were: cellulose morphology (CNC or $\mathrm{CNF}$ ) and concentration ( 0.5 or $1 \mathrm{wt} \%$ ), essential oil concentration ( 20 or $30 \% \mathrm{v} / \mathrm{v})$, rotation speed $(10,000$ or $12,000 \mathrm{rpm})$, and time (3 or 7 minutes).

The emulsions stabilized with cellulose nanocrystals indicated that the CNC concentration and the homogenization speed are not standardized, i.e., these parameters vary and depend on the other conditions to establish an optimal state. The ideal concentration of essential oil was $30 \%$, indicating that in the case of rigid particles (CNC), higher concentrations of $\mathrm{OE}$ are more suitable for the dispersion of drops in smaller sizes and adsorption of CNCs in the interfaces, which can be justified by the volume of radicals available by droplet to interact with the CNCs and keep them adsorbed. The processing time was also a constant for the emulsions studied, and 7 minutes was the most appropriate, reflecting in higher necessary energy for the efficient adsorption of CNCs in the O/W interface.

For the CNF-emulsions, the ideal processing parameters were CNF concentration ( $1 \mathrm{wt} \%$ ) and homogenization speed $(12,000 \mathrm{rpm})$. The CNF concentration is an essential factor in the stable threedimensional network that surrounds oil droplets, being highly dependent on its flexibility and aspect ratio, having a direct relationship with emulsification capacity. A concentration of $1 \%$ was necessary for the suspension to pass to the gel state, and that most drops were well coated, avoiding its coalescence. The high homogenization speed reflects the need for high energy to dissociate the oily phase and breakage into smaller drops.

In summary, the emulsions stabilization by nanocellulose is highly dependent on cellulose morphology, which varies the stabilization mechanism (steric or electrostatic) and directly impacts the $\mathrm{O} / \mathrm{W}$ interface generation. The morphology and cellulose concentration also impact the other process parameters due to the system's energy to achieve equilibrium and irreversible emulsification. This work can act as a template for researchers to understand the influence of Pickering emulsion process parameters and their relationship with solid stabilizer and essential oil, being a guideline for future studies.

\section{Declarations}

The authors declare that they have no known competing financial interests or personal relationships that could have appeared to influence the work reported in this paper. This study does not contain any studies with human participants or animals performed by any of the authors. For this type of study formal consent is not required.

\section{Acknowledgment}


This research was funded by Fundação de Amparo à Pesquisa do Estado de São Paulo (2018/11277-7) and Conselho Nacional de Desenvolvimento Científico e Tecnológico (305819/2017-8). The authors thank the CAPES (Code 001), UFABC, and REVALORES Strategic Unit.

\section{References}

1. Almasi H, Azizi S, Amjadi S (2020) Development and characterization of pectin films activated by nanoemulsion and Pickering emulsion stabilized marjoram (Origanum majorana L.) essential oil. Food Hydrocoll 99:105338. https://doi.org/10.1016/j.foodhyd.2019.105338

2. Angkuratipakorn T, Sriprai A, Tantrawong $S$ et al (2017) Fabrication and characterization of rice bran oil-in-water Pickering emulsion stabilized by cellulose nanocrystals. Colloids Surfaces A Physicochem Eng Asp 522:310-319. https://doi.org/10.1016/j.colsurfa.2017.03.014

3. Bai L, Lv S, Xiang W et al (2019) Oil-in-water Pickering emulsions via microfluidization with cellulose nanocrystals: 1. Formation and stability. Food Hydrocoll 96:699-708. https://doi.org/10.1016/j.foodhyd.2019.04.038

4. Becerril R, Nerín C, Silva F (2020) Encapsulation systems for antimicrobial food packaging components: An update. Molecules 25:. https://doi.org/10.3390/molecules25051134

5. Ben Cheikh F, Mabrouk A, Ben, Magnin A et al (2021) Chitin nanocrystals as Pickering stabilizer for O/W emulsions: Effect of the oil chemical structure on the emulsion properties. Colloids Surfaces $B$ Biointerfaces 200:111604. https://doi.org/10.1016/j.colsurfb.2021.111604

6. Feng X, Dai H, Ma L et al (2020) Properties of Pickering emulsion stabilized by food-grade gelatin nanoparticles: influence of the nanoparticles concentration. Colloids Surfaces B Biointerfaces 196:. https://doi.org/10.1016/j.colsurfb.2020.111294

7. Friberg SE, Larsson K, Joblom JS (2004) Food Emulsions, Fourth Edi. CRC Press, New York

8. Gestranius M, Stenius P, Kontturi E et al (2017) Phase behaviour and droplet size of oil-in-water Pickering emulsions stabilised with plant-derived nanocellulosic materials. Colloids Surfaces A Physicochem Eng Asp 519:60-70. https://doi.org/10.1016/j.colsurfa.2016.04.025

9. Herman A, Tambor K, Herman A (2016) Linalool Affects the Antimicrobial Efficacy of Essential Oils. Curr Microbiol 72:165-172. https://doi.org/10.1007/s00284-015-0933-4

10. Jiménez Saelices C, Capron I (2018) Design of Pickering Micro- and Nanoemulsions Based on the Structural Characteristics of Nanocelluloses. Biomacromol 19:460-469. https://doi.org/10.1021/acs.biomac.7b01564

11. Kalashnikova I, Bizot H, Bertoncini P et al (2013) Cellulosic nanorods of various aspect ratios for oil in water Pickering emulsions. Soft Matter 9:952-959. https://doi.org/10.1039/C2SM26472B

12. Kalashnikova I, Bizot H, Cathala B, Capron I (2011) New pickering emulsions stabilized by bacterial cellulose nanocrystals. Langmuir 27:7471-7479. https://doi.org/10.1021/la200971f

13. Kumar A, Singh P, Gupta V (2020) Application of nanotechnology to boost the functional and preservative properties of essential oils. In: Functional and Preservative Properties of 
Phytochemicals. Elsevier Inc., pp 241-267

14. Li Q, Wang Y, Wu Y et al (2019a) Flexible cellulose nanofibrils as novel pickering stabilizers: The emulsifying property and packing behavior. Food Hydrocoll 88:180-189.

https://doi.org/10.1016/j.foodhyd.2018.09.039

15. Li Y, Wang C, Tao Z et al (2019b) Enhanced Antioxidant and Antiproliferative Activities of Cymbopogon citratus (DC.) Stapf Essential Oils in Microemulsion. https://doi.org/10.1021/acssuschemeng.9b01606

16. Lima GF, Souza AG, Bauli CR et al (2019) Surface modification effects on the thermal stability of cellulose nanostructures obtained from lignocellulosic residues. J Therm Anal Calorim. https://doi.org/10.1007/s10973-019-09109-4

17. Lima GF, Souza AG, Rosa DS (2018) Effect of adsorption of polyethylene glycol (PEG), in aqueous media, to improve cellulose nanostructures stability. J Mol Liq 268:415-424. https://doi.org/10.1016/j.molliq.2018.07.080

18. Lu Y, Li J, Ge L et al (2021) Pickering emulsion stabilized with fibrous nanocelluloses: Insight into fiber flexibility-emulsifying capacity relations. Carbohydr Polym 255:. https://doi.org/10.1016/j.carbpol.2020.117483

19. Lu Y, Qian X, Xie W et al (2019) Rheology of the sesame oil-in-water emulsions stabilized by cellulose nanofibers. Food Hydrocoll 94:114-127. https://doi.org/10.1016/j.foodhyd.2019.03.001

20. Paximada P, Tsouko E, Kopsahelis $\mathrm{N}$ et al (2016) Bacterial cellulose as stabilizer of o/w emulsions. Food Hydrocoll 53:225-232. https://doi.org/10.1016/j.foodhyd.2014.12.003

21. Ribeiro-Santos R, Andrade M, de Melo NR et al (2017) Biological activities and major components determination in essential oils intended for a biodegradable food packaging. Ind Crops Prod 97:201210. https://doi.org/10.1016/j.indcrop.2016.12.006

22. Saffarionpour S (2020) Nanocellulose for stabilization of Pickering emulsions and delivery of nutraceuticals and its interfacial adsorption mechanism. Food Bioprocess Technol. https://doi.org/10.1007/s11947-020-02481-2

23. Shin J, Na K, Shin S et al (2019) Biological activity of thyme white essential oil stabilized by cellulose nanocrystals. Biomolecules 9:1-13. https://doi.org/10.3390/biom9120799

24. Souza AG, Ferreira RR, Paula LC et al (2020) The effect of essential oil chemical structures on Pickering emulsion stabilized with cellulose nanofibrils. J Mol Liq 320:114458. https://doi.org/10.1016/j.molliq.2020.114458

25. Souza AG, Lima GF, Rosa D dos S (2019) Cellulose Nanostructures from lignocellulosic residues. LAP LAMBERT Academic Publishing

26. Tang C, Spinney S, Shi Z et al (2018) Amphiphilic Cellulose Nanocrystals for Enhanced Pickering Emulsion Stabilization. Langmuir 34:12897-12905. https://doi.org/10.1021/acs.langmuir.8b02437

27. Trujillo-Cayado LA, Santos J, Calero N et al (2020) Strategies for reducing Ostwald ripening phenomenon in nanoemulsions based on thyme essential oil. J Sci Food Agric 100:1671-1677. https://doi.org/10.1002/jsfa.10181 
28. Varanasi S, Henzel L, Mendoza L et al (2018) Pickering Emulsions Electrostatically Stabilized by Cellulose Nanocrystals. Front Chem 6:1-9. https://doi.org/10.3389/fchem.2018.00409

29. Yan X, Ma C, Cui F et al (2020) Protein-stabilized Pickering emulsions: Formation, stability, properties, and applications in foods. Trends Food Sci Technol 103:293-303. https://doi.org/10.1016/j.tifs.2020.07.005

30. Yao X, Liu Z, Ma M et al (2018) Control of Particle Adsorption for Stability of Pickering Emulsions in Microfluidics. Small 14:1-7. https://doi.org/10.1002/smll.201802902

31. Yu H, Huang G, Ma Y et al (2021) Cellulose nanocrystals based clove oil Pickering emulsion for enhanced antibacterial activity. Int J Biol Macromol 170:24-32. https://doi.org/10.1016/j.ijbiomac.2020.12.027

32. Zembyla M, Murray BS, Sarkar A (2020) Water-in-oil emulsions stabilized by surfactants, biopolymers and/or particles: a review. Trends Food Sci Technol 104:49-59. https://doi.org/10.1016/j.tifs.2020.07.028

\section{Figures}




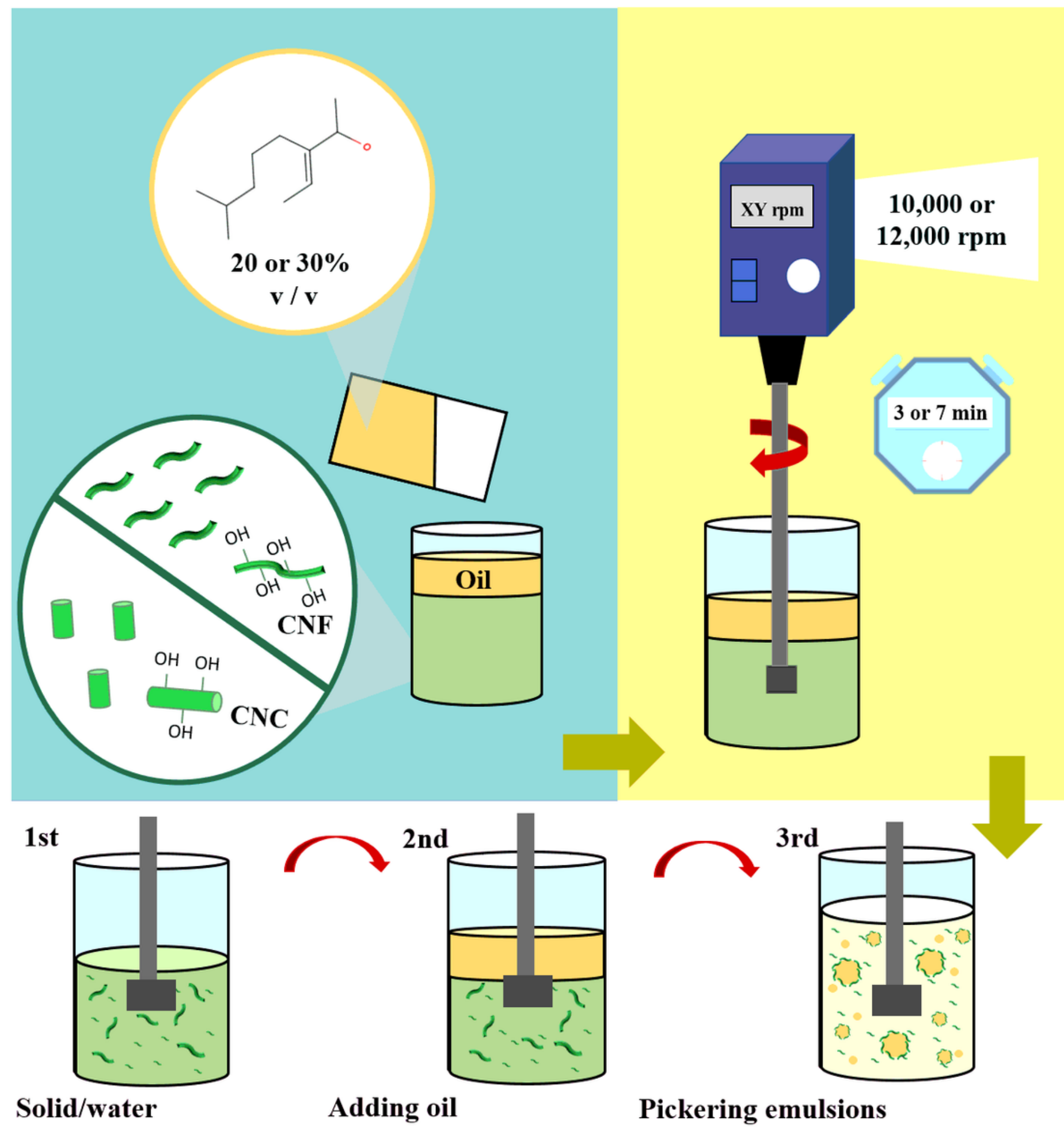

Figure 1

Schematic representation of the adopted methodology for Pickering emulsions obtention. 

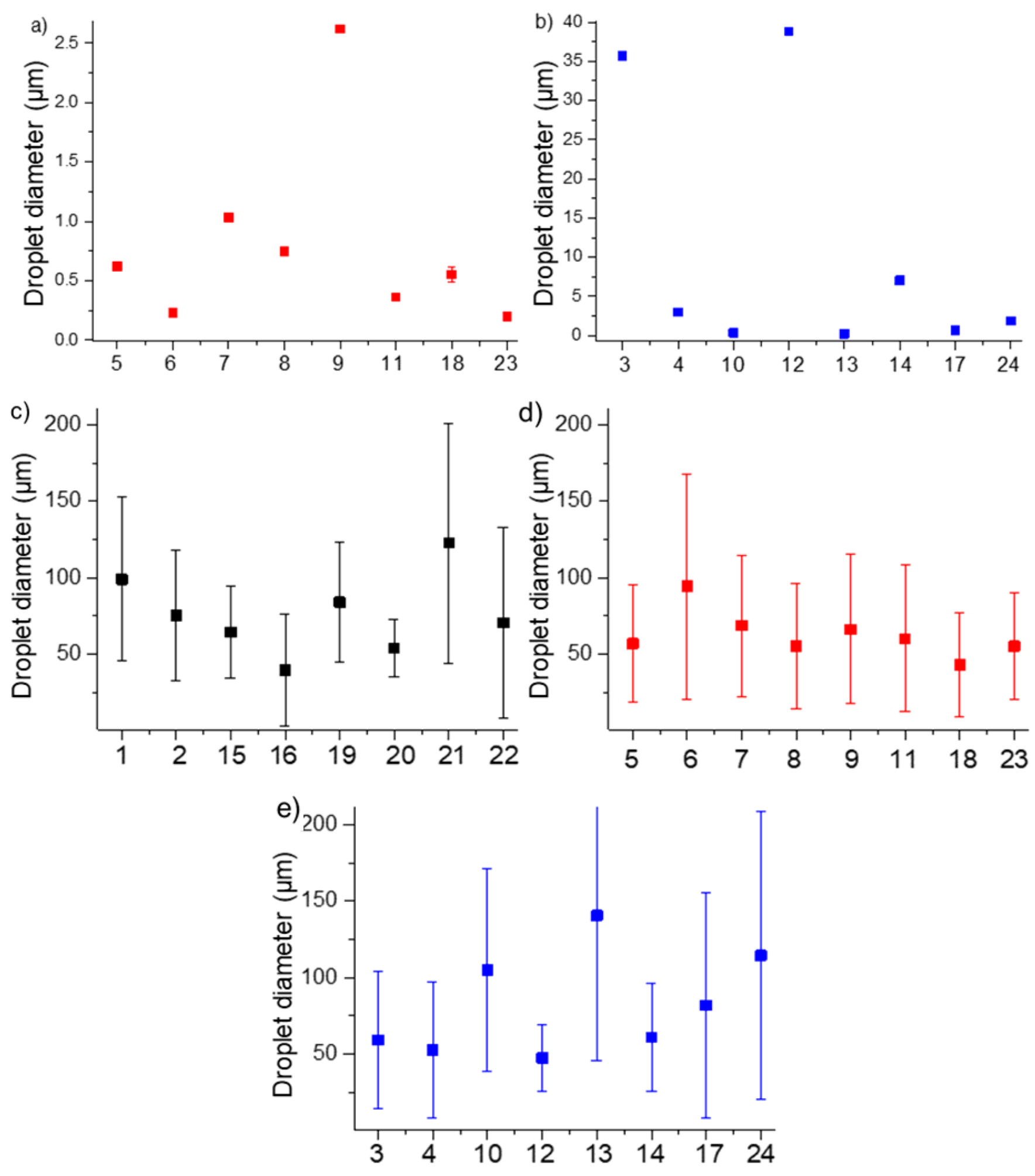

Figure 2

Linalool essential oil emulsions hydrodynamic diameters stabilized by a) CNC and b) CNF, measured by dynamic light scattering technique, and diameters measured by optical microscopy of a) mixtures of nonstabilized linalool and water essential oil, and emulsions stabilized by b) CNC and c) CNF. 


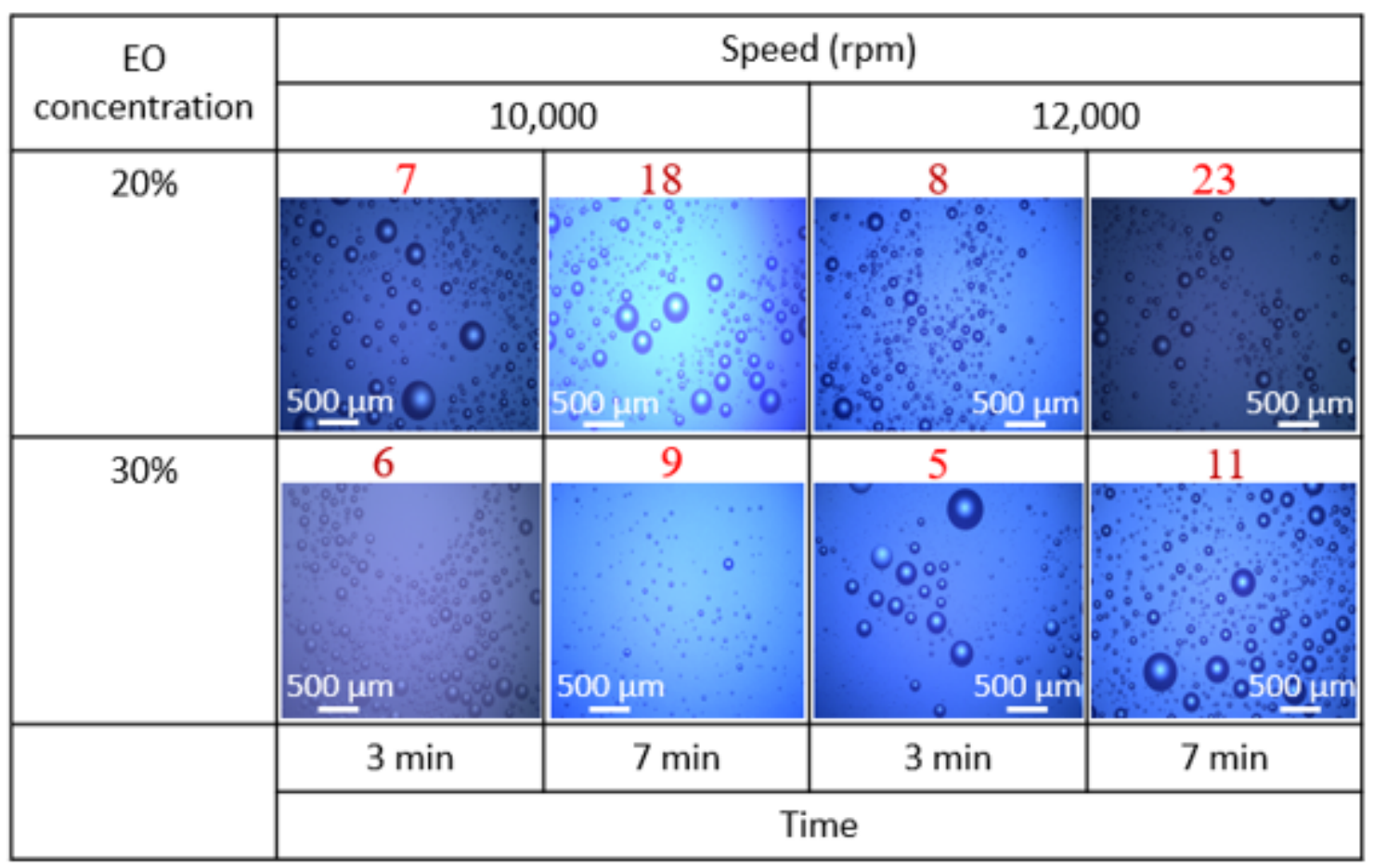

Light red $-1 \%$

Dark red $-0.5 \%$

\section{Figure 3}

Representative photomicrographs obtained by optical microscopy of linalool and water emulsions stabilized with CNC.

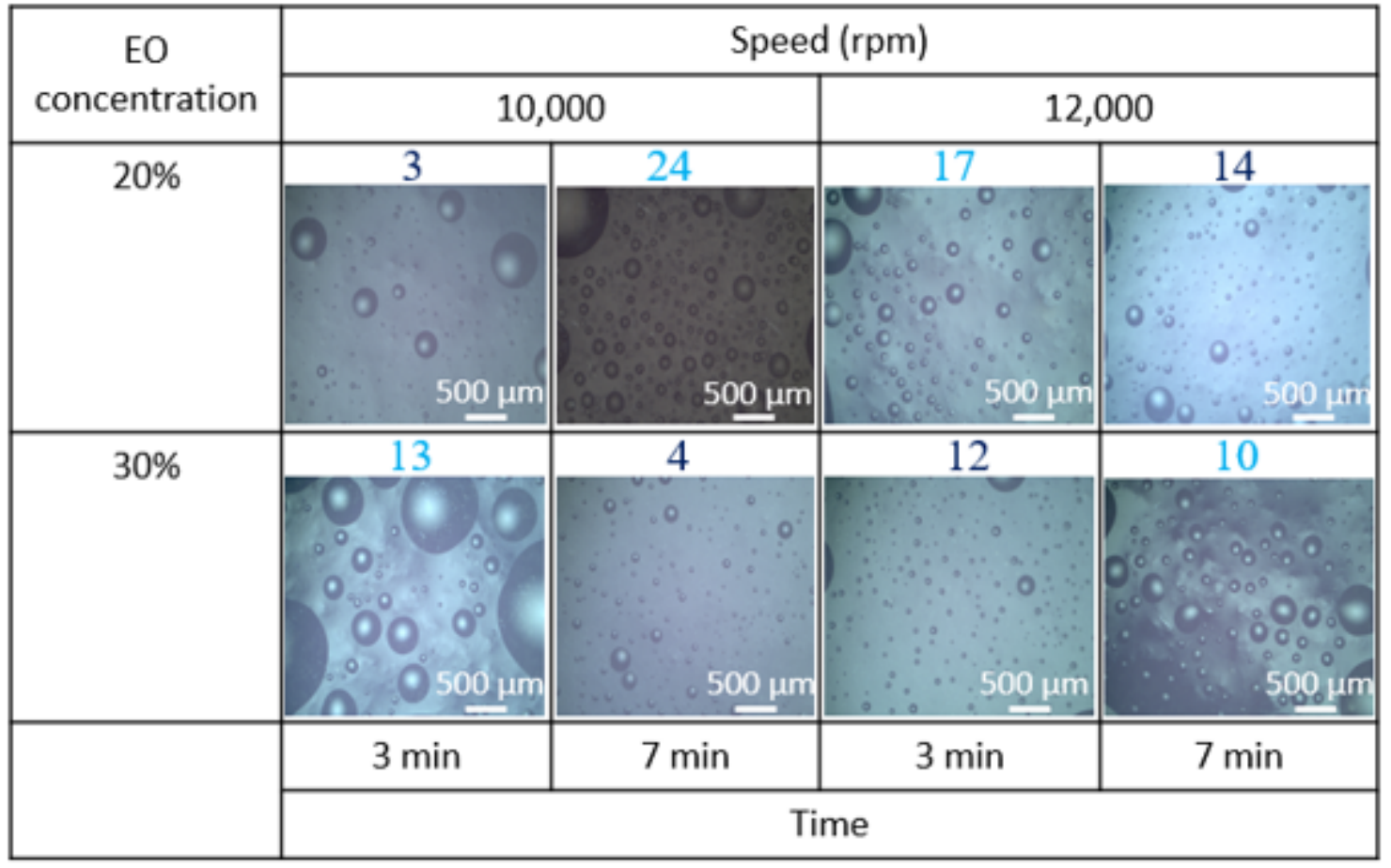

Light blue- $1 \%$

Dark blue- $0.5 \%$

Figure 4 
Representative photomicrographs obtained by optical microscopy of linalool and water emulsions stabilized with CNF.

\begin{tabular}{|c|c|c|c|c|}
\hline \multirow{2}{*}{$\begin{array}{c}\text { EO } \\
\text { concentration }\end{array}$} & \multicolumn{4}{|c|}{ Speed (rpm) } \\
\hline & \multicolumn{2}{|c|}{10,000} & \multicolumn{2}{|c|}{12,000} \\
\hline \multirow[b]{3}{*}{$20 \%$} & 2 & 15 & 1 & 20 \\
\hline & day 0 day 30 & day 0 day 30 & day 0 day 30 & day 0 day 30 \\
\hline & & & & \\
\hline \multirow{5}{*}{$30 \%$} & 16 & 22 & 19 & 21 \\
\hline & day 0 day 30 & day 0 day 30 & day 0 day 30 & day 0 day 30 \\
\hline & & & & \\
\hline & $3 \mathrm{~min}$ & $7 \mathrm{~min}$ & $3 \mathrm{~min}$ & $7 \mathrm{~min}$ \\
\hline & \multicolumn{4}{|c|}{ Time } \\
\hline
\end{tabular}

\section{Figure 5}

Digital photographs obtained from stability over time, on days 0 and 30 , for linalool and water $\mathrm{OE}$ mixtures. 


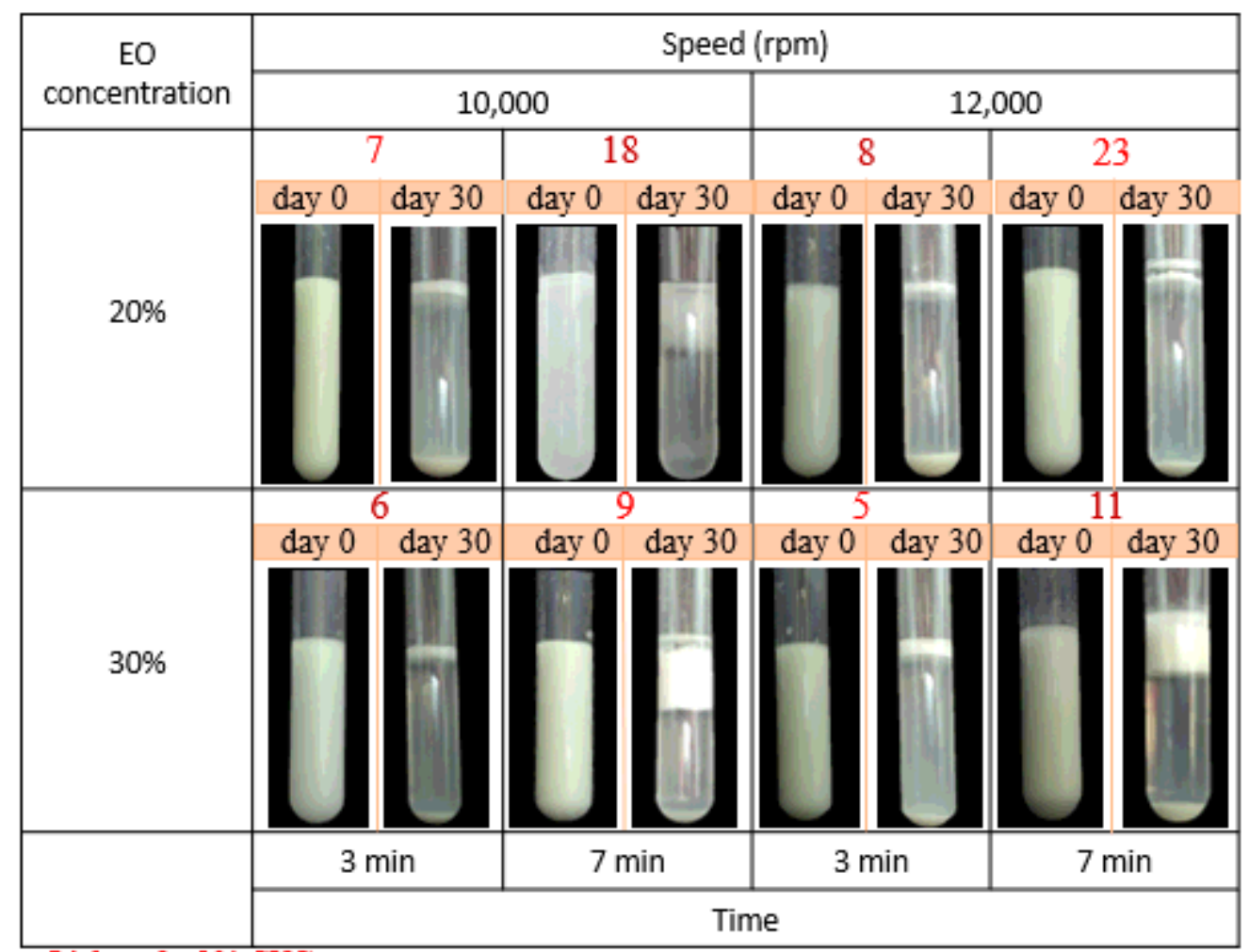

Light red - 1\% CNC

Dark red $-0.5 \% \mathrm{CNC}$

Figure 6

CNC-stabilized emulsions digital photographs obtained from stability over time, on days 0 and 30 .

\begin{tabular}{|c|c|c|c|c|}
\hline \multirow{2}{*}{$\begin{array}{c}\text { EO } \\
\text { concentration }\end{array}$} & \multicolumn{4}{|c|}{ Speed (rpm) } \\
\hline & \multicolumn{2}{|c|}{10,000} & \multicolumn{2}{|c|}{12,000} \\
\hline \multirow[b]{3}{*}{$20 \%$} & 3 & 24 & 17 & 14 \\
\hline & \begin{tabular}{l|l} 
day 0 & day 30
\end{tabular} & day 0 day 30 & day 0 day 30 & day 0 day 30 \\
\hline & t & & & \\
\hline \multirow{4}{*}{$30 \%$} & day $0{ }^{2}$ day 30 & day 0 day 30 & \begin{tabular}{c|c}
12 \\
day 0 day 30
\end{tabular} & $\begin{array}{c}10 \\
\text { day 0 day } 30\end{array}$ \\
\hline & 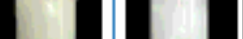 & 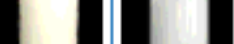 & & \\
\hline & $3 \min$ & $7 \mathrm{~min}$ & $3 \min$ & $7 \mathrm{~min}$ \\
\hline & \multicolumn{4}{|c|}{ Time } \\
\hline
\end{tabular}

Light blue - $1 \% \mathrm{CNF}$

Dark blue - $0.5 \%$ CNF

Figure 7 
CNC-stabilized emulsions digital photographs obtained from stability over time, on days 0 and 30.
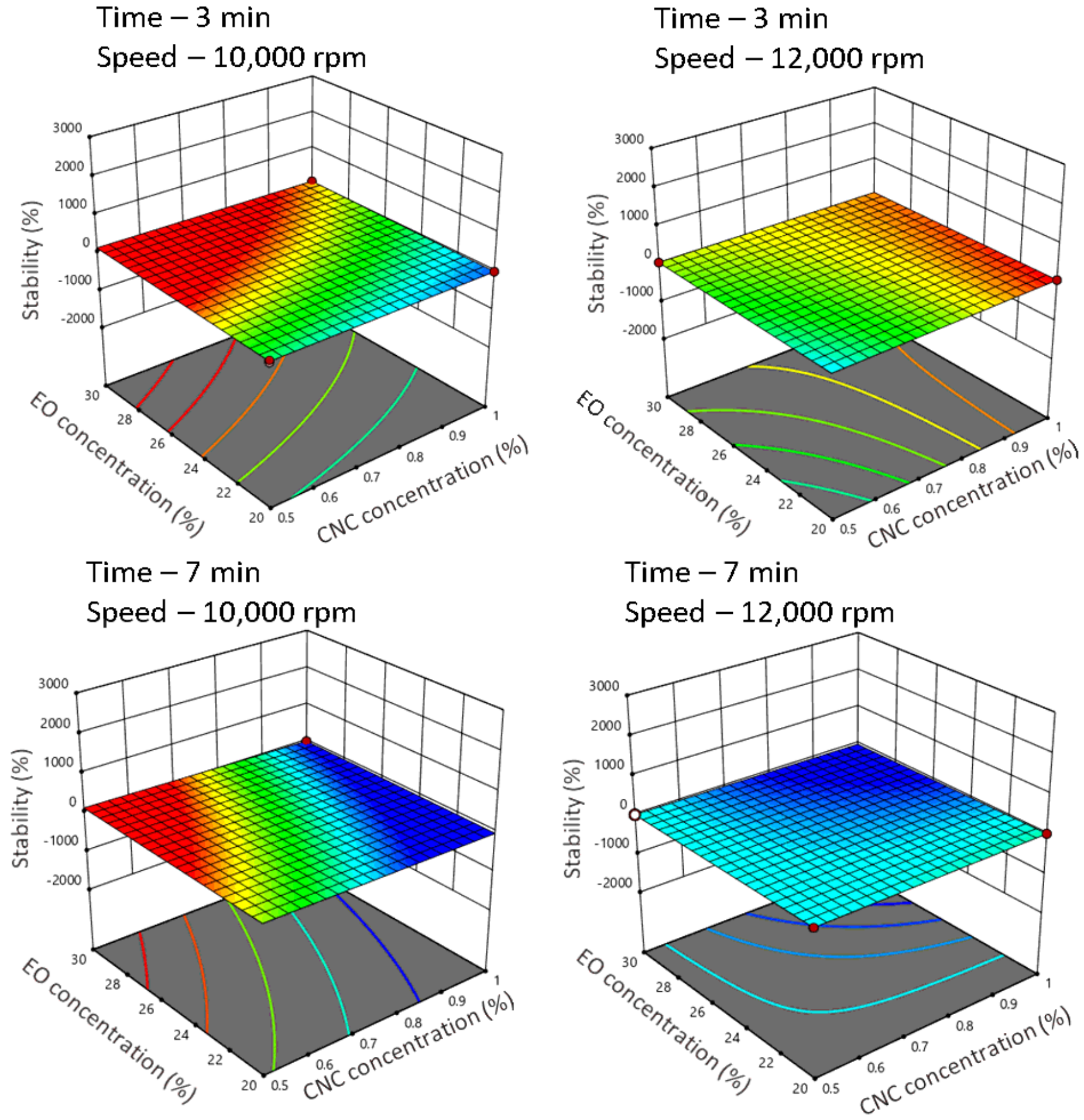

\section{Figure 8}

Effects of CNC concentration, EO concentration, homogenization time, and speed on emulsion stability, analyzed by DoE. 
Time $-3 \mathrm{~min}$

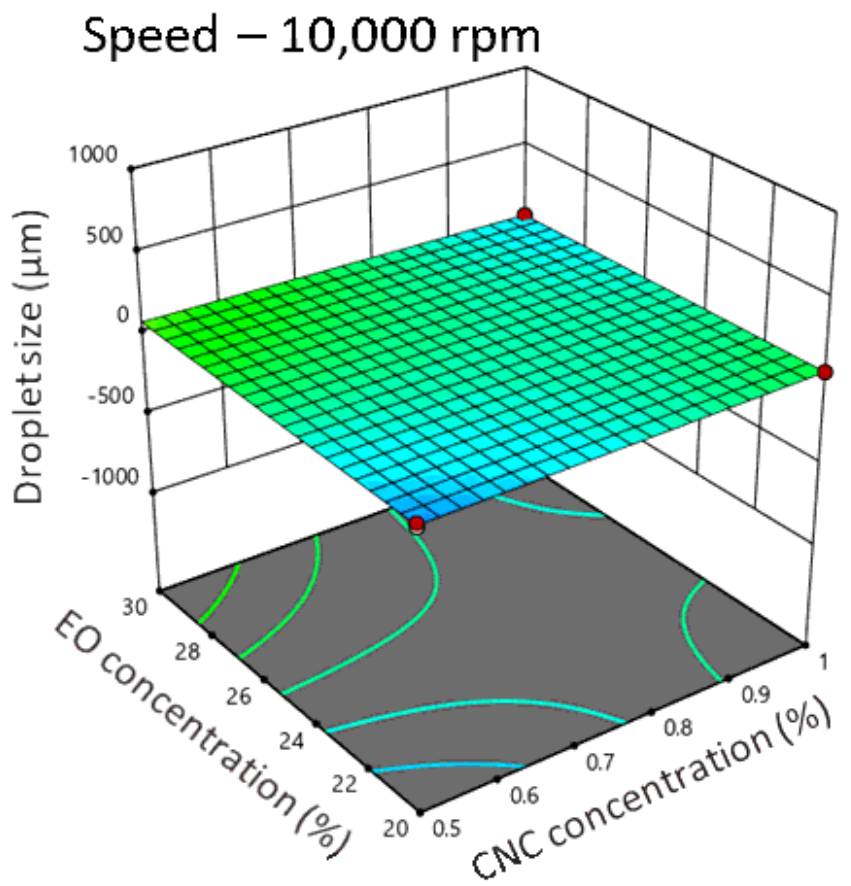

Time $-7 \mathrm{~min}$

\section{Speed $-10,000 \mathrm{rpm}$}

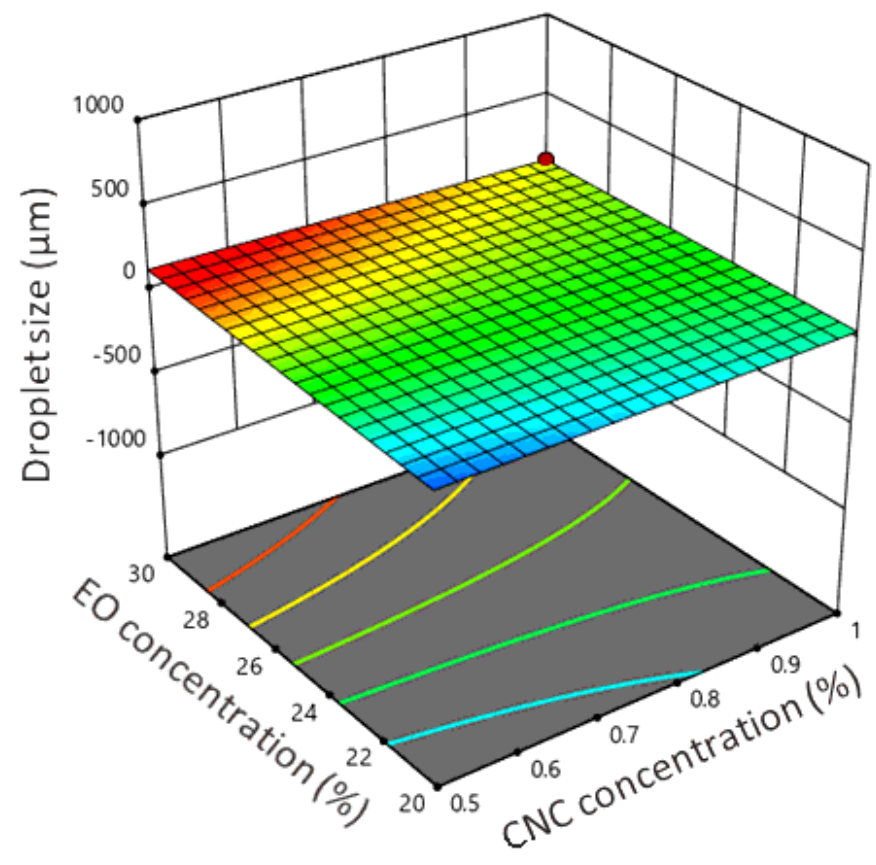

Time $-3 \mathrm{~min}$

Speed $-12,000 \mathrm{rpm}$

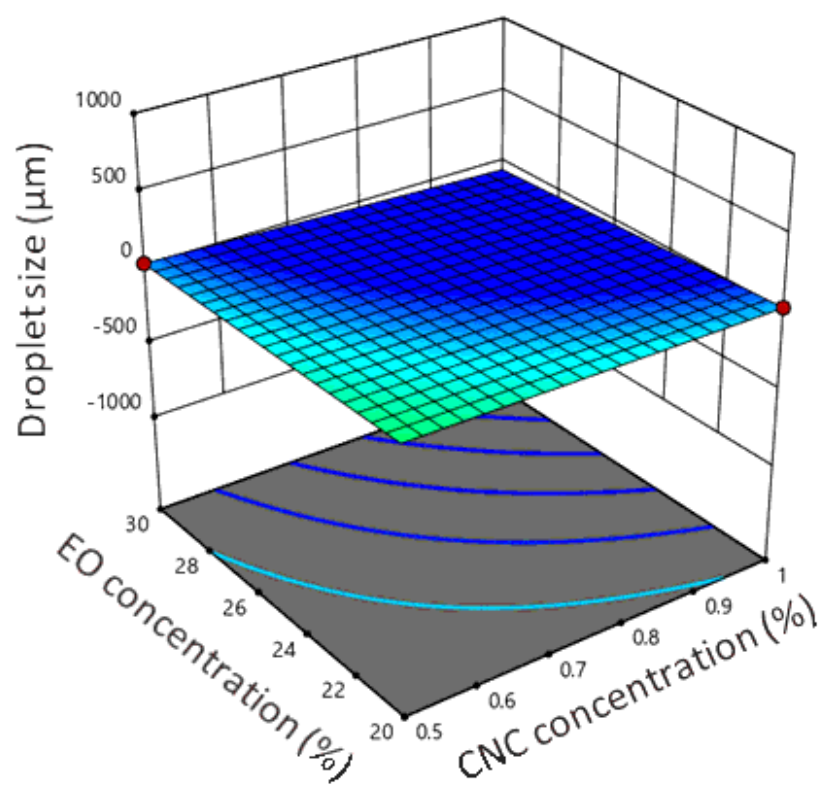

Time $-7 \mathrm{~min}$

Speed $-12,000 \mathrm{rpm}$

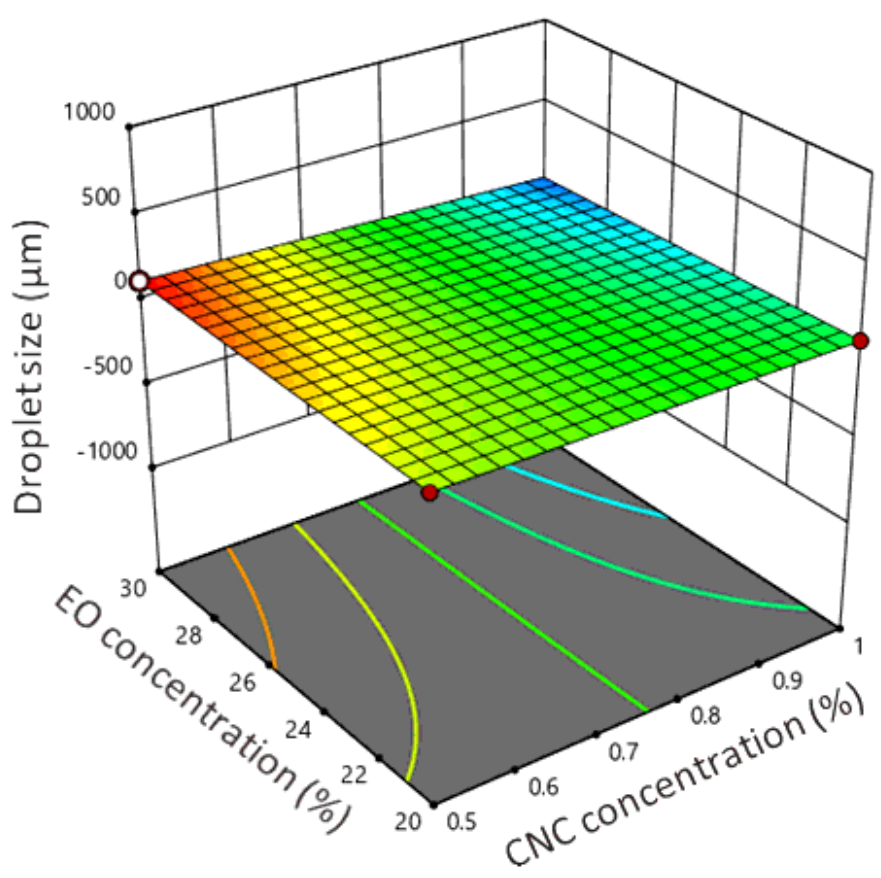

\section{Figure 9}

Effects of CNC concentration, EO concentration, homogenization time, and speed on emulsion droplet size, analyzed by DoE. 

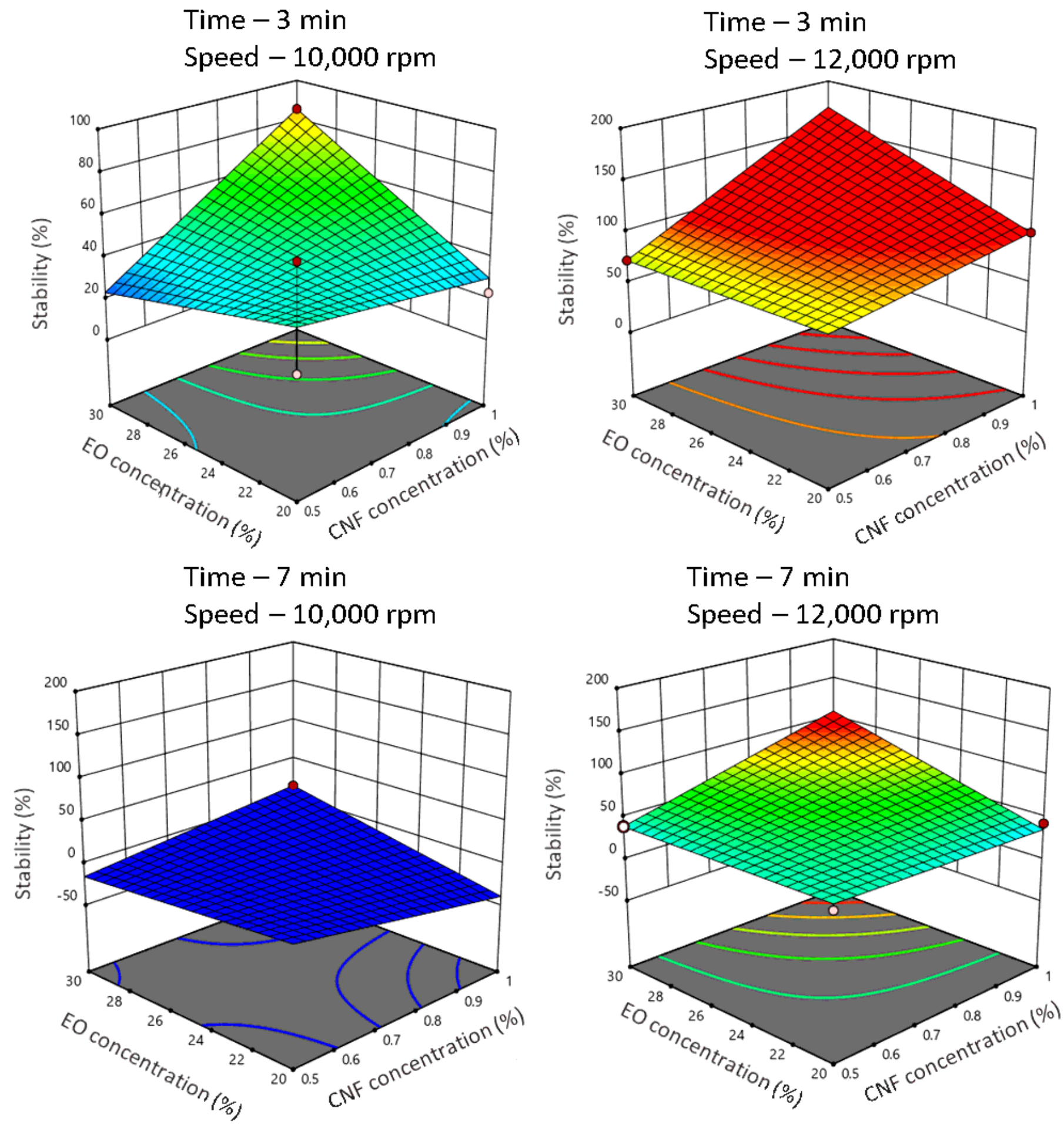

\section{Figure 10}

Effects of CNF concentration, EO concentration, homogenization time, and speed on emulsion stability, analyzed by DoE. 
Time -3 min

Speed $-10,000 \mathrm{rpm}$

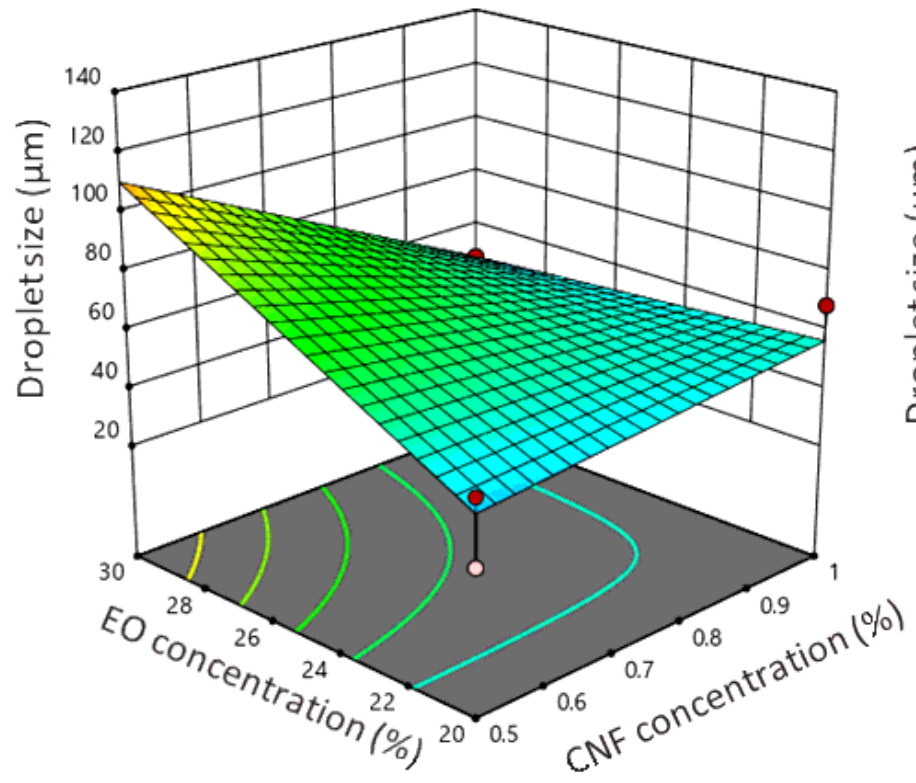

Time $-7 \mathrm{~min}$

Speed $-10,000 \mathrm{rpm}$

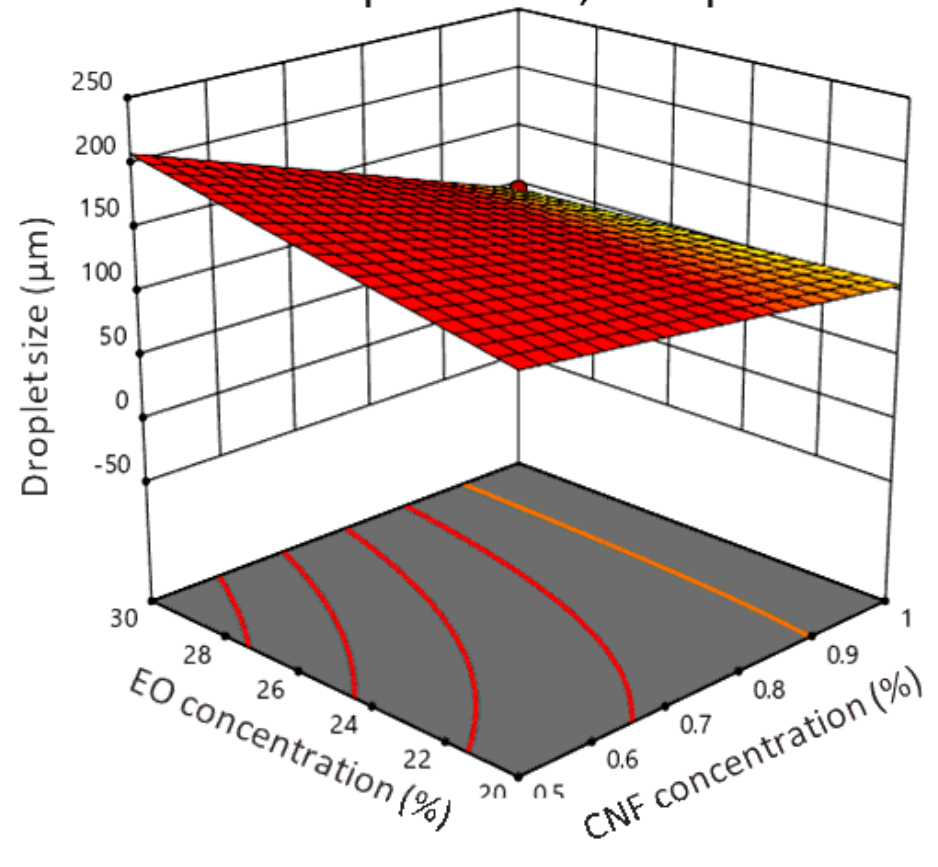

Time $-3 \mathrm{~min}$

Speed $-12,000 \mathrm{rpm}$

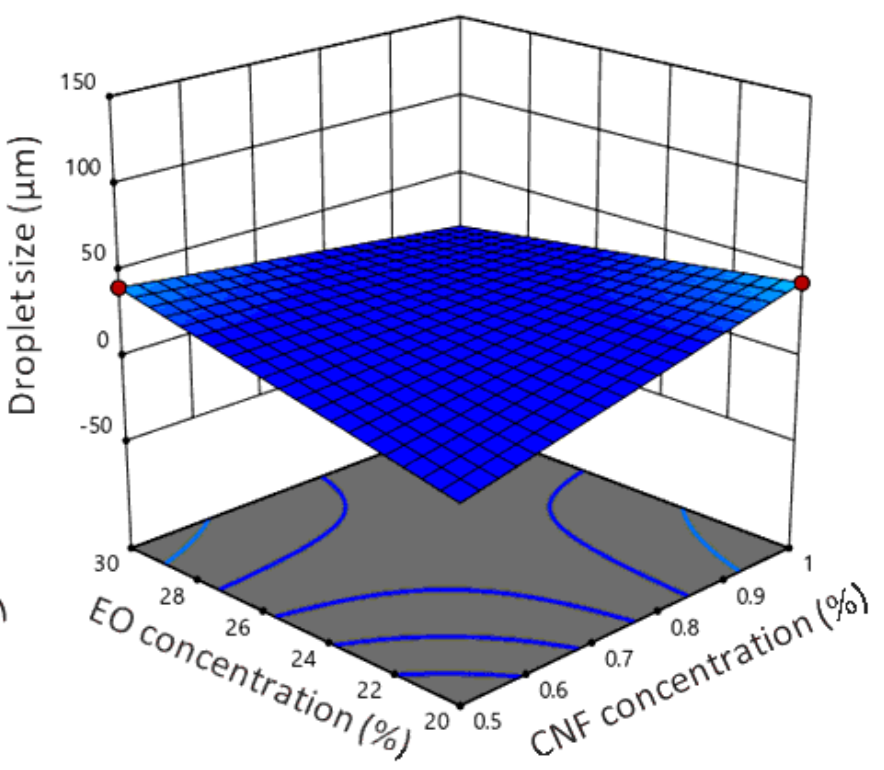

Time $-7 \mathrm{~min}$

Speed $-12,000 \mathrm{rpm}$

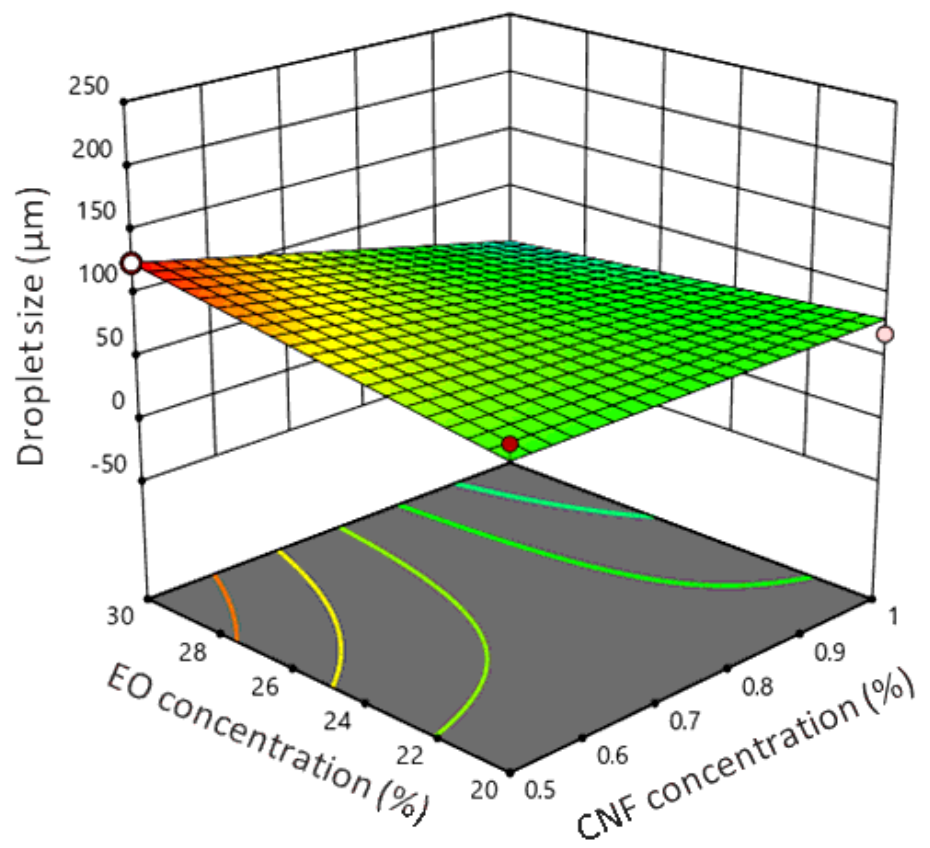

\section{Figure 11}

Effects of CNF concentration, EO concentration, homogenization time, and speed on emulsion droplet size, analyzed by DoE. 


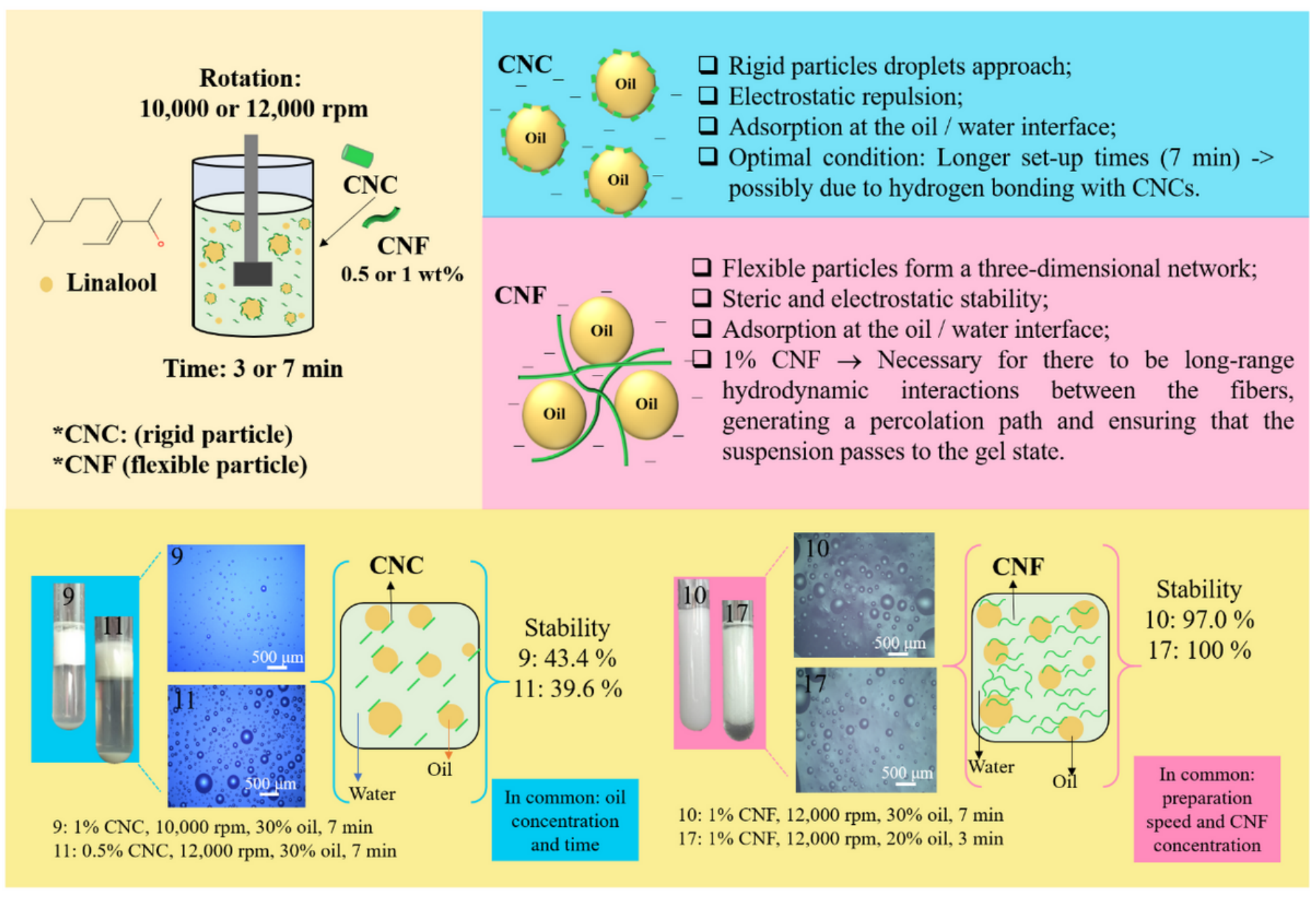

\section{Figure 12}

Schematic representation of the main results found in this work, i.e., the main processing parameters for linalool/nanocellulose-based Pickering emulsion preparation.

\section{Supplementary Files}

This is a list of supplementary files associated with this preprint. Click to download.

- Graphical1.tif

- SupplementaryMaterial.docx 